\title{
Programas de Transferência de Renda e Migração Interna: Evidências do Programa Bolsa Familia
}

\section{Cash Transfer Programs and Intern Migration: Evidence from Bolsa Familia Program}

Luiz Felipe Campos Fontes* Paulo de Andrade Jacinto** Marco Tulio França***

Resumo: O presente trabalho busca estimar os efeitos do Programa Bolsa Família (PBF) sobre a migração inter-regional brasileira. A metodologia aplicada é o Propensity Score Matching (PSM) a partir dos microdados do Censo Demográfico de 2010, em que foi possível analisar indivíduos migrantes, migrantes retornados e não retornados. As estimações apontam que o PBF estimula a remigração dos beneficiários aos seus estados de origem, além de manter aqueles que já estão fixos em uma localidade, mesmo que essa não seja a sua de nascimento. Os resultados não se mostraram sensíveis à possível presença de variáveis omitidas e as demais especificações utilizadas nas estimações. Ao explorar a heterogeneidade regional, mostramos que os impactos sobre remigração e retenção são maiores para o Nordeste, região concentradora de remigrados e beneficiários do PBF. Ainda, por meio da Função Dose Resposta (FDR), mostra-se que os resultados são positivamente correlacionados com os valores monetários pagos pelo programa.

Palavras-chave: Programa Bolsa Família. Migração interna. Propensity score matching. Função dose-resposta.

\begin{abstract}
This work aims to analyze the effects of Bolsa Família Program on Brazilian intern migration. The methodology applied is Propensity Score Matching (PSM) using microdata from Brazilian Census 2010. The results show that the program stimulates recipients' remigration to their home states and retain those already established in a locality. The estimates are robust in the possible presence of omitted variables and in different matching specifications. By exploring regional heterogeneity, we have shown that the impacts on return and retention are greater for the Northeast, the concentrating region of return migrations and Program beneficiaries. Through Dose Response Function it is also shown that the results are positively correlated with the monetary values transfer by the Bolsa Família.
\end{abstract}

Keywords: Bolsa Família Program. Intern migration. Propensity score matching. Doseresponse function.

\footnotetext{
* Mestre em Economia pela Pontifícia Universidade Católica do Rio Grande do Sul (PUCRS). E-mail: luizfelipefontes.80@gmail.com

** Professor do Programa de Pós-Graduação em Desenvolvimento Econômico da Universidade Federal do Paraná (UFPR). E-mail: paulo.jacinto@ufpr.br

*** Professor do Programa de Pós-Graduação em Desenvolvimento Econômico da Pontifícia Universidade Católica do Rio Grande do Sul (PUCRS). E-mail: marco.franca@pucrs.br
} 


\section{Introdução}

No presente estudo, deseja-se mensurar e entender os possíveis incentivos gerados por programas de transferência de renda sobre a migração interestadual interna a partir do Programa Bolsa Família (PBF) no Brasil. Autores como Dustmann e Kirchkamp (2002) sustentam que os fluxos migratórios internos se tornam relevantes na medida em que podem afetar diretamente o bem-estar econômico e a distribuição de renda. No Brasil, o padrão histórico de migração interna mostra indivíduos que deixam regiões pobres em direção às áreas mais desenvolvidas em busca de melhores oportunidades de vida (OLIVEIRA; JANUZZI, 2005). Entretanto, os fluxos migratórios recentes apresentaram importantes diferenças e as regiões pobres, até então emissoras de migrantes, passaram a apresentar forte concentração de remigrados (RAMALHO; QUEIROZ, 2011; QUEIROZ; BAENINGER, 2013; MIRANDA-RIBEIRO; GARCIA; LOBO, 2016). Tais mudanças coincidiram com o aumento da proteção social concedida pelo governo à população, em que se destaca a criação do Programa Bolsa Família em 2004, despertando o interesse em estudar se há uma relação envolvida nesse processo.

Nos estudos de Harris e Todaro (1970) e Borjas (1987), os modelos econômicos clássicos de migração partem da premissa que a decisão de migrar é fruto de uma maximização da renda esperada. Assim, a adição de uma renda não trabalho, como é o caso de uma transferência de renda oriunda de um programa social, poderia impactar tanto na migração quanto na remigração do indivíduo para seu estado de origem.

Evidências empíricas causais sobre programas de transferência de renda e migração interna ainda são escassas. Na literatura internacional, destacam-se dois trabalhos que analisaram essa relação para o programa Oportunidades, no México: Stecklov et al. (2005) e Angelucci (2011). Os autores partiram da premissa de que a migração é diretamente afetada pela renda atual e pela renda futura esperada dos trabalhadores. Assim, o recebimento de um benefício social, que implica uma fonte de renda local para seus beneficiários, impactaria diretamente a decisão de migrar e por consequência os fluxos migratórios agregados.

Em relação à migração interna, Stecklov et al. (2005) argumentam que o acesso à proteção social teria uma correlação positiva com a manutenção de indivíduos em suas regiões, reduzindo o incentivo de migrar para outras localidades. Para Angelucci (2011), este resultado poderia ser potencializado se o desenho do programa impusesse uma barreira quanto à migração. Em contrapartida, a autora levantou a hipótese de que o efeito seria oposto para os fluxos migratórios internacionais. Como a migração é muito dispendiosa neste caso, as transferências de renda podem ajudar a relaxar as restrições de crédito enfrentadas por famílias 
pobres, o que pode levar a uma expansão da migração. Todavia, há de se considerar uma particularidade quanto à região analisada pelos autores devido à intensa migração México-Estados Unidos.

Ambos os estudos supracitados não encontraram impacto do programa sobre os fluxos migratórios internos. ${ }^{1}$ Os resultados de Stecklov et al. (2005) apontaram para um declínio da migração para os Estados Unidos por conta do Oportunidades em regiões tipicamente emissoras de migrantes para o país vizinho. Por sua vez, os resultados de Angelucci (2011) revelaram que o programa influenciou a migração para os Estados Unidos no caso de famílias pobres, vivendo em áreas rurais do México. Como pode ser observado por meio desses dois estudos, não há um consenso quanto aos reais impactos do programa sobre os fluxos migratórios quando se considera o programa Oportunidades.

No Brasil, as evidências são ainda mais escassas. Na literatura nacional, destaca-se o trabalho de Silveira Neto (2008) que testou a hipótese se o PBF influenciava na decisão dos indivíduos quanto à migração interna fazendo uso do Propensity Score Matching (PSM) e dados da Pesquisa Nacional por Amostra de Domicílios (PNAD) de 2004. Os resultados encontrados sugeriram um efeito do programa na retenção quanto à permanência dos beneficiários em seus estados de origem. Porém, não foram encontrados efeitos sobre a migração de retorno interna.

Não abordando especificamente o PBF, Sachsida, Caetano e Albuquerque (2010) buscaram evidências sobre políticas públicas e migração tendo como unidade de avaliação os estados brasileiros. A partir de um painel de dados (20022006) e regressões com efeitos aleatórios, encontraram evidências positivas de transferências federais para as Unidades da Federação (UF) sobre a imigração para estes destinos, indicando que os indivíduos tendem a ir para regiões que receberam um incremento de tais transferências. Os autores evidenciaram também que os fluxos migratórios são negativamente afetados pela concentração de renda. Logo, políticas públicas de transferência de renda no Brasil, como o PBF, podem realmente exercer um papel importante na tomada de decisão dos indivíduos quanto à migração.

A partir dessas considerações, o presente estudo visa verificar a existência e o impacto causal do programa sobre a migração interestadual brasileira sob a hipótese de que o programa pode influenciar tanto na remigração de indivíduos ao estado natal, como na retenção de indivíduos nos estados em que residem. A análise empírica fará uso do método Propensity Score Matching (PSM), o qual vem sendo amplamente utilizado para o estabelecimento de relações causais entre o $\mathrm{PBF}$ e as mais diversas dimensões possíveis a serem influenciadas direta ou indire-

$1 \quad$ Stecklov et al. (2005) utilizou o método de diferenças em diferenças a partir de dados observacionais. Angelucci (2011) utilizou dados da fase piloto do programa para estimar as relações causais de interesse em um contexto experimental. 
tamente pelo programa como, por exemplo, educação, saúde, oferta de trabalho e fecundidade (ARAUJO; RIBEIRO; NEDER, 2010; TAVARES, 2010; UCELLI et al., 2014; BRAW et al., 2015; CECHIN et al., 2015, NASCIMENTO; KASSOUF, 2016; VASCONCELOS et al., 2017). Para investigar os impactos do PBF sobre a migração, também estimamos os resultados sob a hipótese de um tratamento heterogêneo, em que os indivíduos são analisados de acordo com a renda que recebem do programa. Para tanto, buscamos as relações causais do PBF por meio da Função Dose-Resposta (FDR), método até então não explorado na literatura de avaliação do programa.

Assim, além dessa breve introdução, o estudo está estruturado em mais cinco seções. Na segunda seção, discutem-se melhor as hipóteses de que programas de transferência de renda poderiam influenciar nos fluxos migratórios internos. $\mathrm{Na}$ terceira seção é descrita a metodologia utilizada neste estudo. Na quarta, é apresentada a fonte de dados, bem como as estratégias de identificação propostas. Na quinta seção, são reportados os resultados e, por fim, as considerações finais. Os resultados encontrados no presente trabalho apontam para um efeito positivo do programa nas chances dos beneficiários remigrarem para seu estado natal. Também foi encontrado impacto do programa em reter indivíduos em seus estados ao utilizar uma estratégia de identificação comparando apenas os indivíduos que em algum momento da vida já migraram, visando controlar dessa forma as características não observáveis inerentes ao processo migratório. Observou-se ainda que os impactos são acentuados para indivíduos com maiores valores monetários recebidos pelo PBF, o que pode sugerir uma correlação entre os resultados encontrados e a hipótese de maximização de renda apontada pela teoria econômica.

\section{Migração Interna e Programas de Transferência de Renda: Duas Hipóteses}

O Programa Bolsa familia constitui-se na maior política brasileira de assistência social. Instituído pela Lei $n^{\circ}$ 10.836/04 (BRASIL, 2004) o PBF visa atenuar ou reduzir a situação de pobreza ou vulnerabilidade de famílias brasileiras a partir de transferências condicionais de renda. Nesse sentido, o programa assiste aquelas famílias cuja renda domiciliar mensal per capita é igual ou inferior a 70 reais (condição de extrema pobreza) ou cuja renda domiciliar mensal per capita é igual ou inferior a 140 reais (condição de pobreza). Em 2010, o programa atendia a 12,9 milhões de famílias com um orçamento de 14,4 bilhões de reais.

Como diversos trabalhos que buscaram impactos do PBF discutiram também o arcabouço institucional do programa e sua evolução histórica, nos furtamos de demais apresentações relacionadas, ${ }^{2}$ com exceção de um aspecto importante para

2 Para tais informações recomendam-se os seguintes trabalhos: Soares e Sátyro (2010), Cechin et al. (2015), Cavalcanti et al. (2016), Chitolina, Foguel e Menezes-Filho (2016) e Nascimento e Kassouf (2016). 
sustentar uma das nossas hipóteses com respeito à migração que é a Instrução Operacional 12 da SENARC/MDS (BRASIL, 2006). Essa instrução permite à família migrante levar o benefício consigo. Para tanto, basta o responsável legal pela família comunicar ao gestor do programa no município de destino da família. Assim, o valor do benefício financeiro deixa de pertencer à folha de pagamento do município de origem, migrando para a folha de pagamento do município de destino no mês seguinte.

Uma vez apresentado o PBF como o principal programa brasileiro de transferência de renda, pode-se pensar na sua relação com a migração interna que será testada neste estudo seguindo duas hipóteses a serem descritas a seguir.

Hipótese 1: Programas de transferência de renda podem estimular os indivíduos a remigrarem para seu estado natal, uma vez que a proteção social oriunda do programa pode lhes oferecer uma oportunidade de vida que a sua UF de origem, até então, não era capaz de proporcionar. Sendo assim, os beneficiários dessas políticas voltariam para o seu estado natal e evitariam os custos fixos de se estar em outra região.

As evidências empíricas internacionais apontam para o fato de que a migração de retorno faz parte de um planejamento de vida do trabalhador, que sai de seu estado em busca de acúmulo de capital humano/conhecimento/experiências que são benéficas para quando do seu retorno ao local de origem. (DUSTMANN; KIRCHKAMP, 2002; DUSTMANN, 2003; VREYER; GUBERT; ROBILLIARD, 2010; DUSTMANN; MESTRES, 2010).

No Brasil, as evidências mostram o contrário. Os migrantes interestaduais de retorno são jovens, solteiros e com baixo nível de estudo, o que traz a ideia de que a remigração seria fruto de uma frustração quanto à materialização de emprego e renda na região de destino (CUNHA, 2000; BRITO; CARVALHO, 2006). Estudo de Ramalho e Queiroz (2011) aponta para a mesma direção, apesar dos autores mostrarem que o migrante retornado estaria em uma pior situação caso não tivesse migrado no passado.

Teoricamente, estes últimos resultados estariam de acordo com o modelo de Harris-Todaro, em que o migrante retornado seria aquele individuo que passou por uma experiência de migração frustrante, com poucas oportunidades na região de destino, pois, ao comparar os salários esperados entre as localidades, o indivíduo prefere voltar para o seu estado natal. O modelo de Borjas e Bratsberg (1996) faz uma extensão do modelo de Borjas (1987) ao permitir a opção pelo trabalhador à migração de retorno e a conclusão é semelhante: o regresso de indivíduos para sua região de naturalidade é oriunda de um erro de expectativas na região de destino. 
É nesse sentido que programas de transferência condicional de renda teriam efeitos sobre a decisão de remigração do trabalhador. Indivíduos que não conseguiram boas oportunidades no estado de destino podem ser influenciados a voltar ao estado de origem, pois, mesmo que a terra natal não ofereça as melhores condições, o trabalhador tem a sobrevivência garantida por programas sociais do governo, como o Bolsa Família, e ainda pode reencontrar os familiares e evitar demais custos de migração. ${ }^{3}$

Hipótese 2: Programas de transferência de renda estimulariam a permanência de indivíduos já fixos em um estado, independente deste estado ser o de origem do indivíduo. A abordagem econômica mainstream estabelece que a decisão de migração por parte dos agentes ocorre a partir de um cálculo racional com base nos ganhos e custos envolvidos no processo migratório. Sendo assim, a adição de uma renda não trabalho na região de origem, oriunda de um programa social, pode afetar diretamente a probabilidade de migração.

Na hipótese anterior, trabalhamos com a possibilidade de o migrante não conseguir se fixar em um estado de destino e assim ter a sua volta influenciada pelo recebimento de programas de transferência de renda. Entretanto, pode-se pensar também que, uma vez o indivíduo estabelecido na região, o recebimento de programas sociais estimulariam sua manutenção naquele destino.

Seguindo os modelos tradicionais, já comentados, o trabalhador se desloca para uma região, se o salário esperado no destino, diluído dos custos de migração, for maior que o salario esperado na região de origem. Sendo assim, adicionar uma renda não trabalho na região de origem, oriunda de programas sociais, pode diminuir as chances de migração para outro local.

A comparação entre regiões não estabelece a priori que a região de origem deve ser o estado natal do trabalhador. O único empecilho de se estender esta hipótese para um estado que não seja o de origem do individuo seriam os custos fixos de migração. Entretanto, estes tendem a se diluir ao longo do tempo, sendo monetários ou não. Pode-se pensar que no médio ou no longo prazo, o migrante tem condições de trazer a família para perto, reduzir seus custos com moradia, adaptar-se à cultura da região, estabelecer redes de contatos, estabelecer-se em um emprego, entre outros fatores. Portanto, à medida que o indivíduo permanece

3 Embora comum na análise da imigração internacional, as redes sociais, de acordo com Soares (2004) ajudam a reduzir os custos financeiros e físicos da migração. O autor destaca que essas redes são formadas por um conjunto de pessoas que pode estar ligada por relações de parentesco, conhecimento, amizade e de trabalho, constituindo um capital social que traz estabilidade ao fluxo migratório. Fazito (2008) mostra que o estabelecimento de contatos com parentes e conterrâneos pode garantir uma série de aspectos adicionais como hospedagem, oportunidades de trabalho e apoio financeiro no destino. Tais fatores também poderiam justificar o retorno, além da dicotomia entre sucesso e fracasso (FAZITO, 2010). 
em uma região não nativa, o custo de oportunidade para uma nova migração ou retorno torna-se cada vez maior. Se pensarmos na inclusão de um beneficio social nesta região, os custos de oportunidade seriam ainda maiores, considerando o mesmo cálculo econômico-racional discutido anteriormente.

Esta hipótese nos permite testar o efeito de fixação do PBF levando em conta indivíduos que, em algum momento da vida, já arbitraram pela migração. Dessa forma, evita-se a dicotomia migrante versus não migrante que não leva em conta os fatores não observáveis inerentes ao processo migratório. De acordo com Ramalho e Queiroz (2011), 99,6\% da discrepância salarial entre esses grupos, no Brasil, é explicada por características não observáveis.

\section{Metodologia}

Para analisar a relação causal do Programa Bolsa Família sobre uma variável de resultado, torna-se necessário saber o que teria acontecido com indivíduos que receberam o tratamento, caso não tivessem recebido. Entretanto, a principal dificuldade enfrentada na avaliação de políticas públicas advém do fato que não conseguimos observar o contrafactual da unidade tratada. Nesse caso, vieses de seleção podem surgir na avaliação de impactos do programa. ${ }^{4}$

Neste caso, metodologias quase experimentais podem ser utilizadas na busca de indivíduos não beneficiários do programa que sejam os mais próximos possíveis do contrafactual. Neste trabalho, estimaremos a relação entre o PBF e os fluxos migratórios internos por meio do Propensity Score Matching (PSM) pelo qual se busca mitigar os possíveis vieses decorrentes de características observáveis. O parâmetro causal a ser estimado é o efeito médio do tratamento sobre os tratados (Average Treatment Effect on the Treated - ATT).

Adicionalmente, levamos também em conta o fato de que o Programa Bolsa Família paga diferentes valores monetários para seus beneficiários, sendo assim, é um tratamento heterogêneo que pode gerar diferentes incentivos aos indivíduos, de acordo com o grau de exposição destes ao programa. Dessa forma, estimaremos efeitos de tratamento heterogêneo por valor pago pelo PBF com base na Função Dose-Resposta (FDR) de Cerulli e Poti (2014).

\section{IPropensity Score Matching}

O método do PSM consiste em buscar no grupo de controle aqueles mais semelhantes em características observáveis, $X_{i}$, ao grupo de tratados. Entretanto, ao invés de realizar o pareamento a partir de todas as variáveis contidas no

4 Para mais detalhes sobre viés de autosseleção, ver Heckman et al. (1998). 
vetor $X_{i}$, isso é feito pela probabilidade estimada de um indivíduo $i$ ser tratado, denotado por $T_{i}$, com base em $X_{i}$ (ROSENBAUM; RUBIN, 1993). Essa probabilidade, chamada de escore de propensão, é definida como $P\left(X_{i}\right)=\operatorname{Pr}\left(T_{i}=1 \mid X_{i}\right)$, e é tradicionalmente estimada por meio de um modelo probit ou logit. ${ }^{5}$

As hipóteses de identificação são: i) $\mathrm{Y}_{\mathrm{i}}{ }^{1}, \mathrm{Y}_{\mathrm{i}}{ }^{0} \perp \mathrm{T}_{\mathrm{i}} \mid \mathrm{X}_{\mathrm{i}}$; ii) $0<\mathrm{P}\left(\mathrm{X}_{\mathrm{i}}\right)=<1$. A primeira é a hipótese usual de independência condicional das médias, a qual garante que todas as características que afetam a seleção no tratamento estão contidas em $X_{i}$. A segunda estabelece a existência de suporte comum: a probabilidade de achar um indivíduo não tratado para cada indivíduo tratado deve ser maior que zero para todos os possíveis valores de $X_{i}$.

Feita uma pré-seleção de variáveis a serem utilizadas no método, verificou-se o balanceamento do pareamento a partir de dois critérios: analisamos a diferença normalizada de médias entre as variáveis para tratados e controles no sentido de Imbens e Wooldridge (2009); ${ }^{6}$ posteriormente, checamos se havia sobreposição da probabilidade de tratamento para ambos os grupos experimentais.

A estimação dos efeitos pelo Propesity Score Matching é então obtida de acordo com o seguinte estimador:

$$
\hat{\delta}_{a t t}=\frac{1}{n} \sum_{i=1}^{n}\left(Y_{i}-\frac{1}{m} \sum_{j \in C} \omega_{i, j} Y_{j}\right)
$$

onde $n$ é o número de tratados, $i$ é o subscrito para tratado, $j$ é o subscrito para controle, $m$ é o número de matches, $C$ indica suporte comum, $\omega_{i, j}$ é o peso utilizado para parear o indivíduo j ao i e Y é a variável de resultado.

Neste artigo utilizou-se como técnica de pareamento a do vizinho mais próximo em que $\omega_{i, j}$ assume valor igual a 1 para os tratados e seus controles pareados em termos de $P(X)$ e 0 para os demais controles. Além disso, foram consideradas diferentes especificações para o pareamento com intuito de verificar a robustez dos resultados: sem reposição (cada controle da amostra pode ser usado mais de uma vez como match), sem delimitação de diferença máxima entre os escores de propensão para tratados e controles (sem caliper), três valores de caliper distintos $(0,001,0,0005$ e 0,0001) e pareamento com reposição. Vale ainda ressaltar que os erros-padrão foram computados levando em conta o fato de que os escores de

5 A variável de tratamento $T$ é uma dummy de recebimento do PBF. O beneficio do programa é individual e, portanto, consta na base de dados nível indivíduo do Censo. Há de se considerar, no entanto, que o recebimento do benefício por um indivíduo não é independente do recebimento do programa por outros membros de sua família/domicílio. Entretanto isto não é um problema visto que no Censo a variável assume, por natureza, o mesmo valor para todos os que estão em um mesmo domicílio. Nesse sentido, estima-se a probabilidade de o indivíduo i pertencer a um domicílio beneficiário do programa $\left(T_{i}=1\right)$, como comumente feito na literatura de avaliação do PBF - por exemplo: Vasconcelos et al. (2017), Nascimento e Kassouf (2016) e Cechin et al. (2015). Calculadas as médias normalizadas, os autores propõem como diferença admissível entre os grupos valores de 0,25 . 
propensão são estimados em um estágio anterior ao PSM.7 Sendo assim, segue-se a correção proposta por Abadie e Imbens $(2016)^{8}$ o que garante uma maior robustez na estimação do erro padrão da estimativa pontual do ATT.

Diversos outros estimadores que se baseiam na seleção em observáveis poderiam ter sido utilizados, além do escolhido no presente trabalho. Podemos destacar, por exemplo, o PSM com pareamento por kernel, entre os métodos não paramétricos, e as regressões reponderadas por escores de propensão, entre os semiparamétricos. A escolha entre qual método utilizar envolve, em geral, um trade off entre viés e eficiência dos estimadores. O PSM a partir do pareamento pelo vizinho mais próximo, ao selecionar no grupo de controles somente aqueles mais parecidos em características observáveis com os tratados, busca minimizar ao máximo o viés da estimação. Entretanto, neste processo ocorre a perda de algumas observações o que pode acarretar em menor eficiência. Já os métodos citados anteriormente consideram todas as observações dentro do grupo de controle, atribuindo diferentes pesos para cada. Sendo assim, destaca-se como ponto positivo a eficiência destes estimadores. Em contrapartida, ao considerar todos os controles, acaba controlando menos os possíveis vieses por características observáveis e por ausência de suporte comum.

Neste trabalho, optamos então pelo estimador com menor viés possível. Devido ao grande número de observações no Censo Demográfico, acredita-se que a perda de eficiência na estimação será mínima ao utilizar o PSM com pareamento pelo vizinho mais próximo. No entanto, como forma de testar a robustez dos resultados, o ATT também será estimado através do método de regressão linear de resultados potenciais ponderada pelo inverso do escore de propensão (IPW). ${ }^{9}$

\subsection{Análise de Sensibilidade}

Apesar da hipótese levantada anteriormente sobre independência condicional, pode-se pensar na existência de fatores não observáveis que afetem tanto a probabilidade de participação no PBF quanto na probabilidade de migração. Nesse caso, a estimativa do efeito de interesse pode ser inconsistente devido a possível presença de variáveis omitidas, tornando necessário, assim, avaliar a robustez dos resultados, feita normalmente pelo teste conhecido como limites de Rosenbaum.

A probabilidade de um indivíduo participar do tratamento pode ser definida como uma função logística $F(),. P(X)=\operatorname{Pr}\left(\mathrm{T}_{\mathrm{i}}=1 \mid \mathrm{X}_{\mathrm{i}}\right)=\mathrm{F}\left(\beta \mathrm{X}_{\mathrm{i}}+\gamma \mathrm{u}_{\mathrm{i}}\right)$, determinada pelas características observáveis $X_{i}$ e não observáveis $u_{i}$. Na ausência de viés por variável omitida, $\gamma$ será zero e a participação no programa será definida exclusiva-

$7 \quad$ Estimações a partir do comando teffects do Stata.

8 Para mais detalhes, ver também Abadie e Imbens (2006, 2011).

9 Ver Cerulli (2015a) para mais detalhes sobre este e outros métodos de estimação causal. 
mente por $X_{i}$. Na existência de viés, $\gamma$ é diferente de zero e dois indivíduos idênticos em características $X_{i}$ terão diferentes chances de tratamento. Assim, definindo um individuo j pareado a um indivíduo $i$, a razão de chances para que ambos recebam o tratamento, no caso em que $\mathrm{X}_{\mathrm{i}}=\mathrm{X}_{\mathrm{J}}$, é dada por:

$$
\frac{\frac{P\left(X_{i}\right)}{1-P\left(X_{i}\right)}}{\frac{P\left(X_{j}\right)}{1-P\left(X_{j}\right)}}=\frac{P\left(X_{i}\right)\left[1-P\left(X_{i}\right)\right]}{P\left(X_{j}\right)\left[1-P\left(X_{j}\right)\right]}=\frac{F\left(\beta X_{i}+\gamma u_{i}\right)}{F\left(\beta X_{j}+\gamma u_{j}\right)}=\exp \left(\left[\gamma\left(u_{i}-u_{j}\right)\right]\right.
$$

Tem-se viés de seleção por variável omitida, caso a razão de chances seja diferente de 1 . Nesse caso existem diferenças nas características não observáveis, $\mathrm{u}_{\mathrm{i}} \neq \mathrm{u}_{\mathrm{j}}$, que afetam a probabilidade de participação no programa, $\gamma \neq 0$. Rosenbaum (2002), então, sugere analisar os limites da razão de chances de os indivíduos pareados receberem o tratamento, o que pode ser visto a partir da equação (3):

$$
\frac{1}{\tau} \leq \frac{P\left(X_{i}\right)\left[1-P\left(X_{i}\right)\right]}{P\left(X_{j}\right)\left[1-P\left(X_{j}\right)\right]} \leq \tau
$$

onde $\tau=\mathrm{e}^{\mathrm{y}}$.

Quando as variáveis de tratamento e resultado são binárias, Akvik (2001) sugere a utilização do teste estatístico de Mantel-Haenszel para os limites de Rosenbaum, sob a hipótese nula de que o efeito do tratamento é subestimado ou superestimado. Os limites são compostos por $\mathrm{Q}^{+}{ }_{\mathrm{HM}}$, que representa o limite para o caso de o efeito do tratamento ser superestimado, e $Q_{\text {HM }}$ que denota o limite para o caso de o efeito do tratamento ser subestimado. A robustez dos resultados é confirmada na medida em que o teste é rejeitado para diferentes valores de $\tau$.

\subsection{Função Dose-Resposta}

Uma vez que o Bolsa Família destina diferentes valores monetários para os seus beneficiários, os incentivos gerados pela política podem variar de acordo com o grau de exposição do programa pelos indivíduos. Segundo a teoria econômica, a decisão de migração/remigração é fruto de uma maximização de renda entre regiões, sendo assim, valores mais altos de renda oriunda do PBF podem gerar maiores impactos. Tal hipótese pode ser testada a partir da estimação da Função Dose-Reposta $(\mathrm{FDR})^{10}$, a qual mede o impacto causal de uma intervenção de acordo com a exposição dos indivíduos ao programa, medido aqui por meio de rendas monetárias oriundas do PBF.

10 Utiliza-se neste estudo o modelo proposto por Cerulli e Poti (2014), cuja programação em Stata é apresentada em Cerulli (2015b). 
O efeito médio do tratamento (Average Treatment Effect - ATE), dado nível de tratamento $t\left(\mathrm{ATE}_{\mathrm{t}}\right)$ é definido em função de outros parâmetros de interesse causal: o ATT e o efeito médio do tratamento sobre os não tratados (Average Treatment Effect on Non Treated - ATNT). Considerando uma função de resposta ao tratamento $h_{t}$, temos que:

$$
A T E_{t}=\left\{\begin{array}{c}
A T T+\left[h_{t}+h_{t>0}\right] \text { se } t>0 \\
\text { ATNT set }=0
\end{array}\right.
$$

A função de resposta $h_{t}$ é modelada por uma regressão polinomial, que assume a seguinte forma:

$$
h_{t}=a t+b t^{2}+c t^{3}
$$

A partir da regressão de Rubin para os resultados potenciais, assume-se independência condicional das médias e, após manipulações algébricas, o estimador assume a seguinte forma, com $T_{i}$ indicando status de tratamento ${ }^{11}$ :

$$
\begin{aligned}
\widehat{A T E}_{t, l}= & T_{i}\left[\widehat{A T T}+\hat{a}\left(t_{i}-\frac{1}{n} \sum_{i=1}^{n} t_{i}\right)+\hat{b}\left(t_{i}^{2}-\frac{1}{n} \sum_{i=1}^{n} t_{i}^{2}\right)+\hat{c}\left(t_{i}^{3}-\frac{1}{n} \sum_{i=1}^{n} t_{i}^{3}\right)\right] \\
& +\left(1-T_{i}\right) \widehat{A T N T}
\end{aligned}
$$

\section{Dados e Grupos de Comparação}

As evidências empíricas deste trabalho serão geradas a partir dos microdados do Censo Demográfico de 2010. A base de dados apresenta ricas informações sobre migração, contendo uma seção especifica do questionário para esta temática. Além disso, contém informações sobre programas sociais, tornando possível, após a desagregação proposta, identificar os beneficiários do Programa Bolsa Família.

Em um primeiro exercício realizado neste trabalho, propõe-se analisar o impacto do PBF sobre a migração de retorno interestadual interna tendo em vista a hipótese 1 levantada na seção anterior. Para tanto, foram adotadas duas metodologias para classificação dos migrantes: migração de data fixa e migração de última etapa. A partir do primeiro conceito, o migrante é definido como aquele indivíduo que, cinco anos antes do Censo demográfico de 2010, isto é, no ano de 2005, declarou residir em um estado diferente do que ele se encontrava na data da pesquisa (2010). Caso o último seja a sua UF de origem, define-se como migrante de retorno. Já os migrantes de última etapa são aqueles que declararam residência em alguma UF por tempo inferior a 10 anos, sendo que se esta é a sua de nascimento, define-se como migrante retornado. Entretanto, devido à criação do PBF

11 Para exposição completa do método, ver Cerulli e Poti (2014) e Cerulli (2015b). 
em 2004 e realização do Censo em 2010, esse último período será limitado para 6 anos. Tomou-se o cuidado, ainda, de selecionar apenas os indivíduos entre 18 e 70 anos, na busca pela exclusão daqueles que não teriam condições de arbitrar pela migração, chamados de migrantes agregados (SANTOS JÚNIOR; MENEZES-FILHO; FERREIRA, 2005; RAMALHO; QUEIROZ, 2011). Sendo assim, o impacto do PBF sobre a migração de retorno interestadual será medido a partir da construção de variáveis de resultado binárias iguais a 1 para o remigrado ao estado natal e 0 para os demais migrantes. Neste caso, comparam-se os indivíduos que migraram desde a criação do PBF com aqueles que retornaram.

Visando testar a hipótese 2, a qual sugere que o programa manteria seus beneficiários residindo no estado em que estão fixados, propõe-se um segundo exercício: comparar migrantes/remigrantes de longo prazo com aqueles que migraram desde criação do PBF. Para tanto, o primeiro será definido como o indivíduo que declarou ter morado em outra UF, mas que mora na atual localidade há mais de 6 anos (este será denominado como migrante de longo prazo). Seu contrafactual será o mesmo do primeiro exercício, chamado de demais migrantes. Compararemos então indivíduos fixos em um estado (mais de 6 anos de moradia) com indivíduos que migraram no curto prazo (menos de 6 anos de moradia) e que, sendo assim, arbitraram por migrar ou não migrar no mesmo período de tempo - 20042010 (dummy igual a 1 para o indivíduo fixo no estado). Essa estratégia pode ser entendida como um avanço em relação ao trabalho de Silveira Neto (2008) que encontrou impacto negativo do PBF sobre a migração ao comparar migrantes e não migrantes, uma vez que estaríamos estendendo este efeito de retenção inclusive para indivíduos não localizados na sua UF natal. Nota-se ainda que, ao comparar apenas indivíduos que em algum momento da vida já migraram, buscamos mitigar possíveis vieses de seleção por características não observáveis inerentes à decisão de migração, como maior motivação, empreendedorismo e menor aversão ao risco. Nesse sentido, o indivíduo que nunca migrou não parece ser uma unidade de controle adequado para o migrante.

Definidas as variáveis de resultado, torna-se necessário construir um grupo de tratados e controles, utilizados na metodologia proposta pelo trabalho. A partir da variável V0657 contida nos microdados do Censo de 2010 é possível identificar os beneficiários do PBF e do Programa de Erradicação do Trabalho Infantil (PETI). Decidimos então desagregar aqueles indivíduos que participavam do PBF e aqueles que participavam do PETI, o que é feito por meio de estratégia semelhante à proposta por Cechin et al. (2015). O primeiro passo consistiu em selecionar os municípios que recebiam transferências oriundas do PETI em 2010. ${ }^{12}$ Os indivíduos que declararam receber renda oriunda de um dos programas sociais e que esta-

12 Informação obtida junto ao Portal da Transparência. Em 2010, foram constatados 2.966 municípios nos quais havia indivíduos recebendo transferências oriundas do PETI. 
vam em um município no qual ninguém era participante do PETI foram definidos como beneficiários do PBF. Posteriormente, selecionaram-se os indivíduos que recebiam renda oriunda do PBF ou PETI (V6591), mas que não pertenciam a outro programa social (V0658) e que não recebiam renda de outras fontes (V0659). Conseguimos então identificar os beneficiários do PETI como aqueles indivíduos cujas características (domiciliares e municipais) e renda obtida com um dos programas sociais eram compatíveis com as transferências típicas pagas pelo programa, de acordo com alguns critérios. ${ }^{13}$ Os indivíduos cuja compatibilização destes critérios não foi satisfeita foram classificados como beneficiários do PBF.

Os tratados e controles são aqueles indivíduos beneficiários e não beneficiários do PBF, respectivamente. Entretanto, para construção do grupo de controle, nos limitamos aos indivíduos cuja renda domiciliar per capita, oriunda do trabalho, era igual ou inferior a $\mathrm{R} \$ 300,00 .{ }^{14}, 15$ De acordo com Wooldridge (2010), a não participação no programa não garante que todos os indivíduos possam ser enquadrados como grupo de controle, dado que este seria formado por indivíduos que, ceteris paribus, nunca seriam elegíveis para o tratamento, portanto, a população analisada não seria relevante para a avaliação da política pública.

$\mathrm{Na}$ Tabela 1 apresentamos a classificação dos indivíduos entrevistados no Censo quanto à migração, segundo classificação e recorte amostral proposto, para beneficiários e não beneficiários do Programa Bolsa Família. Nota-se que apenas 3,6\% dos indivíduos de baixa renda que migraram nos últimos seis anos eram participantes do PBF em julho de 2010. A participação dos beneficiários do programa é maior quando se analisa a migração de retorno: 10\% do número total de remigrados. Primeiros indícios da relação positiva entre migração de retorno e o Programa Bolsa Família podem ser vistos por meio da razão migrante retornado sobre migrante: 40,8\% para os beneficiários do PBF frente a 13,8\% para os não beneficiários.

13 Os critérios foram: $\mathrm{R} \$ 25,00$ por criança abaixo de 16 anos em municípios na área rural ou urbana, com população inferior a 250.000 habitantes; $R \$ 40,00$ por criança abaixo de 16 anos em capitais, regiões metropolitanas e municípios com população superior a 250.000 habitantes.

14 Exclui-se a renda oriunda de programas sociais, inclusive o Programa Bolsa Família, e de outros rendimentos. Estratégia similar à adotada por Cechin et al. (2015), na qual os autores utilizaram a renda per capita ex ante ao PBF.

15 Foi selecionado um valor de corte um pouco mais de duas vezes acima do valor máximo de elegibilidade ao PBF em 2010 ( $\$$ \$ 140,00 per capita) uma vez que foram encontrados beneficiários do programa cuja renda estava acima do limite. Testaram-se outros valores de corte $(R \$ 150,00, R \$$ 200,00 e $R \$ 250,00$, todos per capita), sem alteração de resultado. 
Tabela 1 - Classificação dos indivíduos quanto à migração para beneficiários e não beneficiários do PBF (migração de última etapa)

\begin{tabular}{lccc}
\hline \multicolumn{1}{c}{ Grupos de análise } & PBF = & PBF $=\mathbf{0}$ & Total \\
\hline Migrante longo prazo* & 634,527 & $8,952,167$ & $9,586,694$ \\
Migrante (M) & 260,407 & $6,889,179$ & $7,149,586$ \\
\hline Migrante Retornado (MR) & 106,296 & 951,669 & $1,057,965$ \\
Demais Migrantes & 154,111 & $5,937,510$ & $6,091,621$ \\
\hline Razão (MR)/(M) & $40.80 \%$ & $13.80 \%$ & $14.80 \%$ \\
\hline
\end{tabular}

Fonte: Elaboração própria a partir dos microdados do Censo 2010.

Nota: Resultados expandidos por meio dos pesos do Censo 2010. Apenas migrantes entre 18 e 70 anos e com renda domiciliar oriunda do trabalho abaixo de 300 reais per capita. * Indivíduos fixos em seu estado há mais de 6 anos, mas que já migraram no passado.

Por fim, apresentam-se no Quadro 1 as variáveis independentes utilizadas nos modelos propostos neste trabalho, as quais foram obtidas ou construídas a partir do Censo Demográfico de 2010. Incluíram-se uma série de variáveis que poderiam afetar tanto o tratamento quanto a variável de resultado, em consonância com literatura padrão sobre ambos os temas.

Quadro 1 - Variáveis independentes utilizadas no Propensity Score Matching e Função Dose-Resposta

\begin{tabular}{|l|l|}
\hline \multicolumn{1}{|c|}{ Variável } & \multicolumn{1}{c|}{ Descrição } \\
\hline Idade & Idade do indivíduo em anos. \\
\hline Idade $^{2}$ & Idade do indivíduo em anos, ao quadrado. \\
\hline Condição no domicílio & $\begin{array}{l}\text { Dummies para as seguintes condições no domicilio: chefe } \\
\text { de domicílio; cônjuge; filho(a)." }\end{array}$ \\
\hline Casado & Dummy igual a 1 se o indivíduo é casado. \\
\hline Sexo & Dummy igual a 1 se o indivíduo é homem. \\
\hline Cor & $\begin{array}{l}\text { Dummies para as seguintes raças: branco; negro/pardo; } \\
\text { indígena. }\end{array}$ \\
\hline Ocupação & $\begin{array}{l}\text { Dummies para as seguintes ocupações de trabalho: tra- } \\
\text { balhador informal; trabalhador autônomo; trabalhador } \\
\text { com carteira assinada; funcionário público; empregador; } \\
\text { economicamente inativo (categoria de referência: desem- } \\
\text { pregado).** }\end{array}$ \\
\hline Fundamental incompleto & $\begin{array}{l}\text { Dummy igual a 1 se o indivíduo possui ensino fundamental } \\
\text { incompleto e assumirá valor igual a 0, caso contrário. }\end{array}$ \\
\hline Fundamental completo & $\begin{array}{l}\text { Dummy igual a 1 se o indivíduo possui ensino fundamental } \\
\text { completo e assumirá valor igual a 0, caso contrário. }\end{array}$ \\
\hline
\end{tabular}




\begin{tabular}{|c|c|}
\hline Variável & Descrição \\
\hline Médio completo & $\begin{array}{l}\text { Dummy igual a } 1 \text { se o indivíduo possui ensino médio com- } \\
\text { pleto e assumirá valor igual a } 0 \text {, caso contrário. }\end{array}$ \\
\hline Superior completo & $\begin{array}{l}\text { Dummy igual a } 1 \text { se o indivíduo possui ensino superior } \\
\text { completo e assumirá valor igual a } 0 \text {, caso contrário. }\end{array}$ \\
\hline Índice de posse & $\begin{array}{l}\text { Índice obtido através do método de análise de } \\
\text { correspondência múltipla, considerando a posse no domicílio } \\
\text { dos seguintes indicadores: energia elétrica; geladeira ou } \\
\text { freezer; televisão; telefone fixo ou celular; máquina de lavar; } \\
\text { computador; carro ou moto. }\end{array}$ \\
\hline $\begin{array}{l}\text { Pessoas domicílio }>15 \\
\text { anos }\end{array}$ & $\begin{array}{l}\text { Número de pessoas no domicilio com idade maior que } 15 \\
\text { anos. }\end{array}$ \\
\hline $\begin{array}{l}\text { Pessoas domicílio }<=15 \\
\text { anos }\end{array}$ & $\begin{array}{l}\text { Número de pessoas no domicilio com idade igual ou me- } \\
\text { nor que } 15 \text { anos. }\end{array}$ \\
\hline $\begin{array}{l}\text { Renda domiciliar per capi- } \\
\text { ta oriunda de trabalho }\end{array}$ & Renda domiciliar per capita em reais oriunda de trabalho. \\
\hline Densidade do domicílio & $\begin{array}{l}\text { Número de indivíduos no domicílio dividido pelo número } \\
\text { de cômodos. }\end{array}$ \\
\hline $\begin{array}{l}\text { Condição de ocupação do } \\
\text { domicílio }\end{array}$ & $\begin{array}{l}\text { Dummies para as seguintes condições de ocupação do } \\
\text { domicilio: próprio, já pago; próprio, não pago; alugado; } \\
\text { cedido por empregador; cedido de outra forma; outra } \\
\text { condição. }\end{array}$ \\
\hline Metrópole & Dummy igual a 1 se região metropolitana. \\
\hline Urbana & $\begin{array}{l}\text { Dummy igual a } 1 \text { se região urbana e assumirá valor igual a } \\
0 \text {, caso rural. }\end{array}$ \\
\hline $\begin{array}{l}\text { Unidades da Federação } \\
\text { (UF) }\end{array}$ & Dummies para UFs. \\
\hline Tempo de moradia na UF & $\begin{array}{l}\text { Tempo de moradia do indivíduo, em anos, na UF em que } \\
\text { reside. }\end{array}$ \\
\hline
\end{tabular}

Fonte: Elaboração própria a partir dos microdados do Censo 2010.

Nota: * Na amostra final não foram encontrados indivíduos nas condições de outros familiares ou demais agregados, como empregado doméstico ou pensionista. * * Na amostra final não foram encontrados militares.

\section{Resultados}

Nesta seção apresentaremos os resultados empíricos do trabalho. Começamos apresentando estimativas que visam testar às hipóteses levantadas na seção 2 . Posteriormente, exploramos a heterogeneidade regional dos resultados, conduzimos análises de robustez e, por fim, mostramos a heterogeneidade dos resultados de acordo com o valor pago pelo PBF ao beneficiário. 


\subsection{Testando as Hipóteses Levantadas}

Os resultados a seguir são apresentados de forma a descrever a hipótese 1 e a hipótese 2, levantadas neste trabalho para especificar de que maneira o Programa Bolsa Família teria efeitos sobre a migração interna no Brasil. Para o teste empírico da primeira hipótese, apresenta-se o Exercício I, enquanto que para a segunda, o Exercício II.

\subsubsection{Exercíciol}

O primeiro exercício feito neste trabalho consistiu em estimar o impacto do Programa Bolsa Família sobre a migração de retorno tendo em vista os conceitos de migração de última etapa e data fixa. Sendo assim, para a aplicação do método PSM, estimamos a probabilidade de os indivíduos participarem do Programa Bolsa Família por meio de um modelo logit binomial, para ambas as amostras (Tabela 9, no apêndice). ${ }^{16}$ Todos os parâmetros estimados seguem o sinal esperado e confirmam que os beneficiários do programa são aqueles indivíduos mais carentes em termos socioeconômicos. Feito o pareamento, analisamos o critério de balanceamento entre os grupos no sentido de Imbens e Wooldrige (2009). Na Tabela 10 do apêndice pode-se observar que todas as variáveis utilizadas estão balanceadas, sugerindo que os tratados e controles são, em média, semelhantes. Na Figura 1 percebe-se que antes do pareamento os grupos experimentais eram distintos em características observáveis. Com o pareamento, a distribuição da probabilidade de tratamento para ambos os grupos é quase idêntica, sugerindo uma boa adequação do modelo e maior robustez para estimação do ATT.

16 A estimação do modelo logit é praticamente idêntica para as amostras dos migrantes de última etapa e data fixa. Sendo assim, apresentamos somente o resultado da primeira. 
Figura 1 - Distribuição da probabilidade de tratamento para tratados e controles antes e após o pareamento pelo método do vizinho mais próximo com reposição

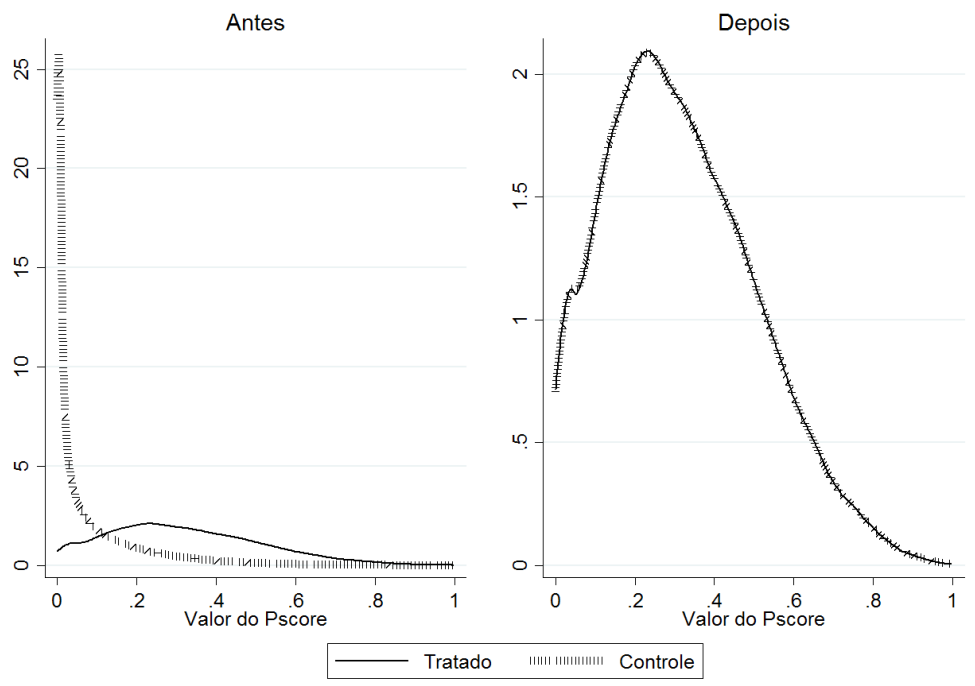

Fonte: Elaboração própria.

A Tabela 2 apresenta os efeitos do PBF sobre a migração de retorno interna no Brasil. As estimativas apontam que os beneficiários do programa têm mais chances de serem retornados ao estado natal. Para a migração de última etapa (coluna 1), a estimação foi de $2,9 \%$ no modelo base e se manteve para formas mais restritas de pareamento, cujo ATT estimado variou de $2,6 \%$ a 3,0\%. O efeito é semelhante quando a migração é analisada a partir do conceito de data fixa (coluna 2): 2,4\% para o pareamento sem caliper e com reposição e variando de 2,3 a $2,7 \%$ a partir das demais especificações. Sendo assim, a probabilidade de os beneficiários do programa serem remigrados ao estado natal é, aproximadamente, 3 p.p superior em comparação aos não beneficiários do programa, semelhantes em diversas características observáveis. 
Tabela 2 - Estimação dos efeitos do PBF (ATT) sobre a migração de retorno interestadual

\begin{tabular}{lcc}
\hline \multirow{2}{*}{ Especificação } & Estimativa pontual e erro padrão \\
\cline { 2 - 3 } & $\mathbf{( 1 )}$ & $\mathbf{( 2 )}$ \\
\hline S/Caliper & $0.029 * * *$ & $0.025^{* * *}$ \\
& $(0.0041)$ & $(0.0039)$ \\
\hline Observações & 348,109 & 317,757 \\
\hline Caliper 0,001 & $0.028 * * *$ & $0.024 * * *$ \\
& $(0.0041)$ & $(0.0039)$ \\
\hline Observações & 348,063 & 317,724 \\
\hline Caliper 0,0005 & $0.028 * * *$ & $0.023 * * *$ \\
& $(0.0041)$ & $(0.0039)$ \\
\hline Observações & 348,008 & 317,655 \\
\hline Caliper 0,0001 & $0.026 * * *$ & $0.023 * * *$ \\
& $(0.0041)$ & $(0.0039)$ \\
\hline Observações & 347,221 & 316,913 \\
\hline S/ Reposição & $0.030^{* * * *}$ & $0.027 * *$ \\
& $(0.0015)$ & $(0.0039)$ \\
\hline Observações & 348,109 & 317,757 \\
\hline
\end{tabular}

Fonte: Elaboração própria.

Nota: ** ${ }^{*}<0.01,{ }^{* *} \mathrm{p}<0.05, * \mathrm{p}<0.1$. Erros padrões robustos entre parênteses, com correção de Abadie e Imbens (2016). Na coluna (1) a variável de resultado é baseada no conceito de migração de última etapa e na coluna (2) no conceito de migração de data fixa.

\subsubsection{Exercício II}

Neste exercício é testada a hipótese de que o PBF incentivaria os beneficiários a continuarem residindo na UF em que estavam fixos, independente dessa ser a sua ou não de nascimento. Para tanto, comparamos os indivíduos que migraram/ remigraram no passado e desde a criação do PBF (2004) não migraram mais (chamados aqui de migrantes de longo prazo) com os que migraram no período 20042010 (dummy igual a 1 para os indivíduos fixos no seu estado a mais de 6 anos).

Estimamos a probabilidade de os indivíduos dessa amostra participarem do PBF. Os resultados são bem semelhantes aos encontrados anteriormente e podem ser vistos na Tabela 11 no apêndice. O critério de balanceamento do pareamento também foi confirmado, uma vez que tratados e controles pareados são semelhantes em relação a todas as variáveis utilizadas (Tabela 12, no apêndice). Na Figura 2, verifica-se que após o pareamento a distribuição de probabilidade estimada é 
muito semelhante entre os grupos, o que permite mitigar possíveis vieses de seleção por características observáveis e ausência de suporte comum.

Figura 2 - Distribuição da probabilidade de tratamento para tratados e controles antes e após o pareamento pelo método do vizinho mais próximo com reposição

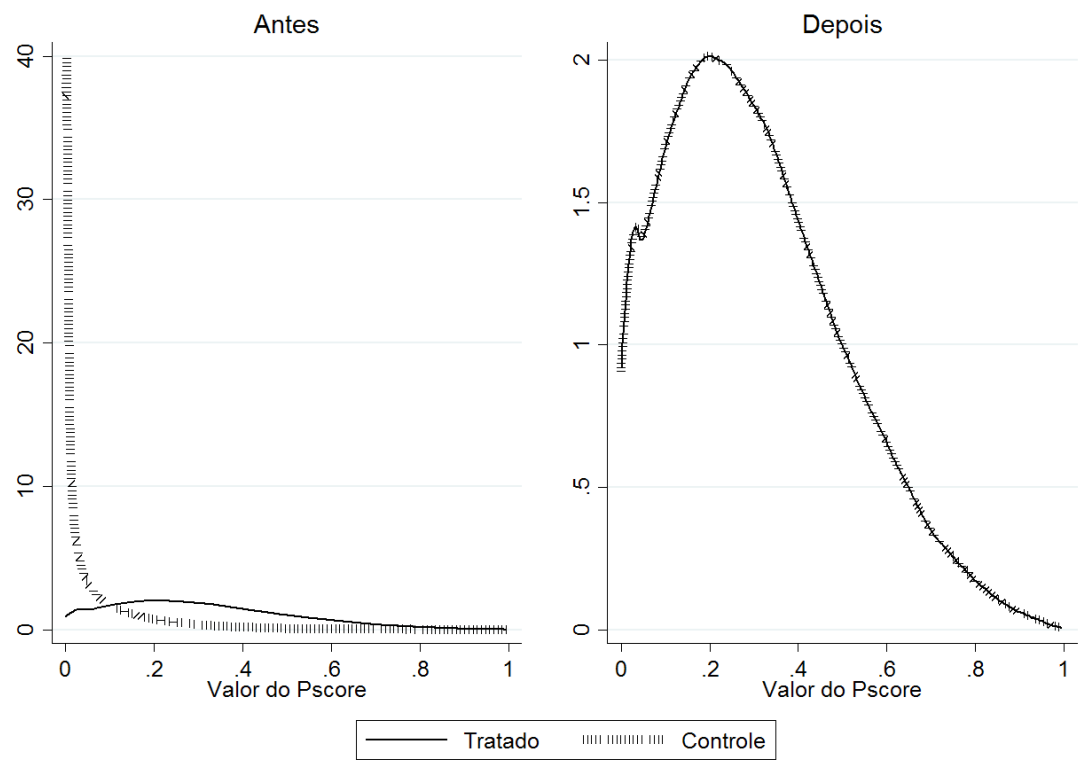

Fonte: Elaboração própria

Na Tabela 3 observa-se que para a nova variável de resultado o impacto do $\mathrm{PBF}$ foi positivo, ou seja, ele incentivou que os indivíduos continuassem no estado em que já moravam, antes da criação do PBF. A estimação do ATT aponta para um efeito de $2,8 \%$ no caso do pareamento sem caliper e com reposição, confirmado também em modelos alternativos (impacto variando de $2,5 \%$ a $2,8 \%$ ). Sendo assim, a probabilidade de os beneficiários do Bolsa Família estarem fixos no estado em que se localizam é 2,8 p.p superior à probabilidade dos não beneficiários. 
Tabela 3 - Estimação dos efeitos do PBF (ATT) sobre a retenção de indivíduos fixos em um estado há mais de seis anos

\begin{tabular}{lc}
\hline \multicolumn{1}{c}{ Especificação } & Estimativa pontual e erro padrão \\
\hline S/ Caliper & $0.028^{* * *}$ \\
\hline Observações & $(0.0011)$ \\
\hline Caliper 0,001 & $1,629,923$ \\
\hline Observações & $0.027^{* * *}$ \\
\hline Caliper 0,0005 & $(0.0011)$ \\
\hline Observações & $1,629,911$ \\
\hline Caliper 0,0001 & $0.027 * *$ \\
& $(0.0011)$ \\
\hline Observações & $1,629,848$ \\
\hline S/ Reposição & $0.027 * *$ \\
\hline Observações & $(0.0011)$ \\
\hline
\end{tabular}

Fonte: Elaboração própria.

Nota: *** $\mathrm{p}<0.01, * * \mathrm{p}<0.05,{ }^{*} \mathrm{p}<0.1$. Erros padrões robustos entre parênteses, com correção de Abadie e Imbens (2016).

\subsection{Explorando a Heterogeneidade Regional}

Após estabelecer as relações referentes às hipóteses sugeridas no presente estudo para o Brasil como um todo, ampliamos a análise para recortes amostrais por região com intuito de explorar a heterogeneidade existente ao longo do território nacional. Na Tabela 13 do Apêndice A é apresentada a proporção de participantes do PBF, bem como dos demais grupos de migração utilizados neste trabalho em relação às cinco regiões brasileiras. Nota-se a existência de uma maior concentração de beneficiários do programa nas regiões Nordeste (32\%) e Norte $(24,8 \%)$, consideradas as duas regiões mais carentes em temos socioeconômicos. Os fluxos migratórios são mais intensos nas regiões Nordeste e Sudeste em que observa-se, na primeira, a maior concentração de remigrados $(40,2 \%)$ ao passo que a segunda apresenta o maior número de imigrantes (30,3\%). O Sudeste é também a região com a maior proporção de indivíduos fixos há mais de seis anos em sua UF de moradia atual, mas que já migraram no passado $(39,21 \%)$. 
$\mathrm{Na}$ tabela 4 apresentamos os efeitos do programa sobre a remigração de indivíduos para cada uma das cinco regiões. ${ }^{17}$ As estimativas pontuais são maiores para a região Nordeste, concentradora de beneficiários do programa e de migrantes de retorno. O ATT estimado para esta região variou de $4,8 \%$ a 5,5\%, bem acima da estimação média apresentada anteriormente (3\%). Resultados estatisticamente significantes foram encontrados sobre a remigração de indivíduos para as regiões Norte e Sudeste. Para a primeira a estimativa pontual variou de 1,9 a $2,2 \%$ e se manteve significante a $1 \%$. Para a segunda o ATT estimado variou de $1 \%$ a 1,3\% mas só se manteve significante a 10\%, o que garante uma menor robustez ao resultado.

Tabela 4 - Estimação dos efeitos do PBF (ATT) sobre a migração de retorno interestadual (Exercício I) - recorte amostral por região

\begin{tabular}{|c|c|c|c|c|c|}
\hline Especificação & Norte & Nordeste & $\begin{array}{c}\text { Centro- } \\
\text { Oeste }\end{array}$ & Sudeste & Sul \\
\hline \multirow{2}{*}{ S/ Caliper } & $0.019 * *$ & $0.048 * * *$ & 0.004 & $0.013^{* *}$ & 0.018 \\
\hline & $(0.008)$ & $(0.006)$ & $(0.008)$ & $(0.006)$ & (0.016) \\
\hline Observações & 40,870 & 95,072 & 56,921 & 108,570 & 51,030 \\
\hline \multirow{2}{*}{ Caliper 0,001 } & $0.022 * *$ & $0.049 * * *$ & 0.002 & $0.013 * *$ & 0.0012 \\
\hline & $(0.009)$ & $(0.006)$ & $(0.008)$ & $(0.006)$ & $(0.016)$ \\
\hline Observações & 40,234 & 94,456 & 56,545 & 107,984 & 50,243 \\
\hline \multirow{2}{*}{ Caliper 0,0005 } & $0.020 * *$ & $0.049 * * *$ & 0.001 & $0.012 *$ & 0.009 \\
\hline & $(0.009)$ & $(0.006)$ & $(0.008)$ & $(0.006)$ & $(0.017)$ \\
\hline Observações & 40,134 & 94,354 & 56,084 & 107,215 & 49,954 \\
\hline \multirow{2}{*}{ Caliper 0,0001 } & $0.020 * *$ & $0.050 * * *$ & 0.001 & $0.011 *$ & 0.008 \\
\hline & $(0.009)$ & $(0.006)$ & $(0.008)$ & $(0.006)$ & $(0.017)$ \\
\hline Observações & 39,946 & 94,087 & 55,957 & 106,953 & 49,245 \\
\hline \multirow{2}{*}{ S/ Reposição } & $0.022 * *$ & $0.055^{* * *}$ & 0.000 & $0.010^{*}$ & 0.005 \\
\hline & (0.009) & (0.009) & $(0.008)$ & $(0.006)$ & $(0.011)$ \\
\hline Observações & 39,568 & 93,864 & 55,534 & 106,647 & 48,934 \\
\hline
\end{tabular}

Fonte: Elaboração própria.

Nota: *** $\mathrm{p}<0.01,{ }^{* *} \mathrm{p}<0.05,{ }^{*} \mathrm{p}<0.1$. Erros padrões robustos entre parênteses, com correção de Abadie e Imbens (2016).

17 Uma vez confirmado anteriormente que os efeitos são semelhantes independentemente do conceito de migração utilizado - ultima etapa e data fixa - utilizou-se para as estimações regionais apenas o primeiro conceito. 
Na Tabela 5 observam-se os efeitos regionalizados de retenção do PBF sobre a migração. Os impactos são maiores para a região Nordeste, cujo ATT estimado variou de $3,9 \%$ a $4,2 \%$. Nesse sentido, além do PBF ter efeito significativo sobre a remigração de indivíduos para os estados nordestinos, também estimula a permanência daqueles que já estão fixos na região por mais de 6 anos. Efeito similar foi encontrado para as regiões Norte, Nordeste e Sul. Para as duas primeiras, as estimações foram muito semelhantes, variando de 1,9\% a 2,3\% e se mantendo robustas a 1\% de significância para todas as especificações. Para a região Sul o efeito retenção encontrado variou de $1,5 \%$ a 1,8\%, significativos a $5 \%$. É curioso notar a ausência de resultado para a região Sudeste, apesar de a mesma concentrar 23,2\% dos beneficiários do programa e 39,2\% dos migrantes de longo prazo (fixos na UF por mais de 6 anos). Nesse sentido, as estimações auferidas neste estudo não parecem ser fruto de mera composição amostral.

Tabela 5 - Estimação dos efeitos do PBF (ATT) sobre a retenção de indivíduos (Exercício II) - recorte amostral por região

\begin{tabular}{|c|c|c|c|c|c|}
\hline Especificação & Norte & Nordeste & $\begin{array}{c}\text { Centro- } \\
\text { Oeste }\end{array}$ & Sudeste & Sul \\
\hline \multirow{2}{*}{ S/ Caliper } & $0.022 * * *$ & $0.043 * * *$ & $0.021 * * *$ & 0.003 & $0.018 * *$ \\
\hline & $(0.008)$ & $(0.004)$ & $(0.005)$ & $(0.004)$ & (0.009) \\
\hline Observações & 251,941 & 285,887 & 224,301 & 573,243 & 193,280 \\
\hline \multirow{2}{*}{ Caliper 0,001 } & $0.022 * * *$ & $0.043 * * *$ & $0.021 * * *$ & 0.001 & $0.018 * *$ \\
\hline & $(0.004)$ & $(0.004)$ & $(0.005)$ & $(0.004)$ & $(0.004)$ \\
\hline Observações & 251,877 & 285,744 & 224,112 & 573,102 & 193,280 \\
\hline \multirow{2}{*}{ Caliper 0,0005 } & $0.022 * * *$ & $0.042 * * *$ & $0.021 * * *$ & 0.021 & $0.016 * *$ \\
\hline & $(0.004)$ & $(0.004)$ & (0.004) & $(0.004)$ & $(0.005)$ \\
\hline Observações & 251,583 & 285,654 & 223,004 & 573,025 & 193,280 \\
\hline \multirow{2}{*}{ Caliper 0,0001 } & $0.022 * * *$ & $0.039 * * *$ & $0.022 * * *$ & 0.000 & $0.016 * *$ \\
\hline & $(0.004)$ & $(0.004)$ & $(0.004)$ & $(0.004)$ & $(0.004)$ \\
\hline Observações & 251,015 & 285,409 & 223,501 & 572,756 & 193,280 \\
\hline \multirow{2}{*}{ S/ Reposição } & $0.019 * * *$ & $0.042 * * *$ & $0.023 * *$ & 0.000 & $0.015^{* *}$ \\
\hline & $(0.003)$ & $(0.004)$ & $(0.005)$ & $(0.003)$ & $(0.008)$ \\
\hline Observações & 251,941 & 285,795 & 224,301 & 573,104 & 193,280 \\
\hline
\end{tabular}

Fonte: Elaboração própria.

Nota: ${ }^{* *} \mathrm{p}<0.01,{ }^{* *} \mathrm{p}<0.05,{ }^{*} \mathrm{p}<0.1$. Erros padrões robustos entre parênteses, com correção de Abadie e Imbens (2016). 


\subsection{Análise de Robustez}

A análise realizada até esse momento deu ênfase nas características observáveis nos fluxos migratórios. Contudo, há possibilidade da presença de fatores não observáveis envolvidos nesses fluxos, exigindo uma análise complementar para verificar se as estimações realizadas neste trabalho são robustas na possível presença de variáveis omitidas. Sendo assim, apresentamos na Tabela 6 a análise de sensibilidade dos resultados via limites de Rosenbaum. Para todas as variações propostas em $\tau\left(\mathrm{e}^{\eta}\right)$ a hipótese de superestimação do ATT é rejeitada ao nível de significância de $5 \%$, considerando as três estimações realizadas neste trabalho. Beneficiários e não beneficiários do Programa Bolsa Família e que já migraram para outro estado poderiam então diferir na probabilidade de participação no tratamento em até $100 \%$ devido a fatores não observáveis (pouco provável de acontecer), que os resultados ainda se manteriam robustos.

Tabela 6 - Análise de sensibilidade dos limites de Rosenbaum (teste de MantelHaenszel)

\begin{tabular}{cccc}
\hline & $\begin{array}{c}\text { Exercício I } \\
\text { Última etapa }\end{array}$ & $\begin{array}{c}\text { Exercício I } \\
\text { Data Fixa }\end{array}$ & Exercício II \\
\hline 1 & 0 & 0 & 0.0024 \\
1.1 & $<0.0001$ & 0 & $<0.0001$ \\
1.2 & $<0.0001$ & 0.0003 & 0 \\
1.3 & 0.0397 & 0.0456 & 0 \\
1.4 & $<0.0001$ & $<0.0001$ & 0 \\
1.5 & 0 & 0 & 0 \\
1.6 & 0 & 0 & 0 \\
1.7 & 0 & 0 & 0 \\
1.8 & 0 & 0 & 0 \\
1.9 & 0 & 0 & 0 \\
2 & 0 & 0 & 0 \\
\hline
\end{tabular}

Fonte: Elaboração própria.

Nota: p valor para o limite de superestimação do efeito do tratamento.

Analisamos também, via limites de Rosembaum, a sensibilidade das estimações auferidas em nível regional. Para o impacto sobre a remigração de indivíduos para as regiões Norte e Nordeste, os resultados se mantiveram robustos até o nível $\tau=1,3$. Nesse sentido, tratados e controles poderiam diferir em até $30 \%$ na probabilidade de participação no programa por conta da possível presença de variáveis omitidas, que os resultados ainda se manteriam robustos. Se considerarmos o nível 
de significância de $10 \%$, os resultados para a região Sudeste se mantém robustos mesmo na possível presença de variáveis omitidas. Caso prefira se avaliar o teste a 5\% de significância, então tratados e controles poderiam diferir em até 10\% na probabilidade de participação do programa por conta da possível omissão de regressores relevantes. Para o Exercício II, referente ao efeito retenção, o teste via limites de Rosenbaum aponta que as estimações auferidas para as regiões Norte, Nordeste e Centro-Oeste são todas robustas mesmo na possível presença de variáveis omitidas. Para a região Sul, o teste não foi significante para o nível $\tau=1,1 \mathrm{o}$ que garante pouca robustez para o resultado no caso de um possível problema de endogeneidade. 
Tabela 7 - Análise de sensibilidade dos limites de Rosenbaum (teste de MantelHaenszel) - recorte amostral por região

\begin{tabular}{|c|c|c|c|c|c|}
\hline & \multicolumn{5}{|c|}{ Exercício I } \\
\hline & Norte & Nordeste & $\begin{array}{c}\text { Centro- } \\
\text { Oeste }\end{array}$ & Sudeste & Sul \\
\hline 1 & 0 & 0 & - & $<0.0001$ & - \\
\hline 1.1 & $<0.0001$ & $<0.0001$ & - & 0.0793 & - \\
\hline 1.2 & $<0.0001$ & 0.0072 & - & 0.06021 & - \\
\hline 1.3 & 0.01929 & 0.2243 & - & $<0.0001$ & - \\
\hline 1.4 & $<0.0001$ & $<0.0001$ & - & $<0.0001$ & - \\
\hline 1.5 & 0 & $<0.0001$ & - & 0 & - \\
\hline 1.6 & 0 & 0 & - & 0 & - \\
\hline 1.7 & 0 & 0 & - & 0 & - \\
\hline 1.8 & 0 & 0 & - & 0 & - \\
\hline 1.9 & 0 & 0 & - & 0 & - \\
\hline \multirow[t]{3}{*}{2} & 0 & 0 & - & 0 & - \\
\hline & \multicolumn{5}{|c|}{ Exercício II } \\
\hline & Norte & Nordeste & $\begin{array}{c}\text { Centro- } \\
\text { Oeste }\end{array}$ & Sudeste & Sul \\
\hline 1 & $<0.0001$ & 0 & $<0.0001$ & - & 0.0015 \\
\hline 1.1 & 0 & 0 & 0 & - & 0.1914 \\
\hline 1.2 & 0 & 0 & 0 & - & $<0.0001$ \\
\hline 1.3 & 0 & 0 & 0 & - & $<0.0001$ \\
\hline 1.4 & 0 & 0 & 0 & - & 0 \\
\hline 1.5 & 0 & 0 & 0 & - & 0 \\
\hline 1.6 & 0 & 0 & 0 & - & 0 \\
\hline 1.7 & 0 & 0 & 0 & - & 0 \\
\hline 1.8 & 0 & 0 & 0 & - & 0 \\
\hline 1.9 & 0 & 0 & 0 & - & 0 \\
\hline 2 & 0 & 0 & 0 & - & 0 \\
\hline
\end{tabular}

Fonte: Elaboração própria.

Nota: $\mathrm{p}$ valor para o limite de superestimação do efeito do tratamento. As colunas vazias se referem às estimações regionais para o ATT que não foram estatisticamente significantes e para as quais, portanto, testes de robustez não foram estimados.

Na Tabela 14 do Apêndice A são apresentadas estimações para o ATT (Brasil e regiões) relacionado ao Exercício I e II, utilizando como método a regressão linear ponderada pelo inverso do score de propensão (IPW). Nota-se que por esse mode- 
lo o efeito estimado do PBF sobre a remigração foi de 3,8\% enquanto que sobre a retenção de 4,5\%. Em nível regional, os resultados foram de $2 \%$ para a região Norte e 4,8\% para o Nordeste, no caso do Exercício I; e de 3,1\% para a região Norte, 4,5\% para o Nordeste, 2,7\% para o Centro-Oeste e 1,3\% para o Sul, no caso do Exercício II. Esses resultados são, qualitativamente, semelhantes aos apresentados anteriormente, apesar de alguns coeficientes apresentarem magnitude superior àqueles estimados via PSM. Tal fato se relaciona com a discussão apresentada na seção 3 sobre os métodos de estimação causal, em que se destacou o PSM com pareamento por vizinho mais próximo como um estimador menos viesado que o IPW.

Por fim, na Tabela 8 apresentam-se as estimações do ATT ${ }^{18}$ e o teste de sensibilidade de Rosenbaum para os Exercícios I e II considerando somente a migração dos chefes de domicílio. Uma vez que as estimações até aqui realizadas são a nível indivíduo e, sendo assim, consideraram todos os agregados domiciliares, poder-se-ia questionar a significância dos resultados. Entretanto, nota-se pela Tabela 8 que os resultados são os mesmos, além de robustos, em uma amostra que só considera os chefes de domicílio.

18 Consideramos nesta estimação o pareamento sem caliper e com reposição. 
Tabela 8 - Estimação dos efeitos do PBF (ATT) sobre a migração de retorno (Exercício I) e retenção (Exercício II) e análise de sensibilidade dos limites de Rosenbaum, em uma amostra considerando somente chefes de domicílio.

\begin{tabular}{ccc}
\hline Estimação & Exercício I & Exercício II \\
\hline Estimativa Pontual & $0.029^{* * *}$ & $0.028^{* * *}$ \\
Erro Padrão & $(0.008)$ & $(0.003)$ \\
\hline$\tau$ & \multicolumn{2}{c}{ P valor } \\
\hline 1 & $<0.0001$ & $<0.0001$ \\
1.1 & $<0.0001$ & $<0.0001$ \\
1.2 & 0.02366 & 0.01193 \\
1.3 & 0.06772 & 0.03831 \\
1.4 & $<0.0001$ & $<0.0001$ \\
1.5 & 0 & 0 \\
1.6 & 0 & 0 \\
1.7 & 0 & 0 \\
1.8 & 0 & 0 \\
1.9 & 0 & 0 \\
2 & 0 & 0 \\
\hline Observações & 135,496 & 813,274 \\
\hline
\end{tabular}

Fonte: Elaboração própria.

Nota: ** $\mathrm{p}<0.01,{ }^{* *} \mathrm{p}<0.05,{ }^{*} \mathrm{p}<0.1$. Erros padrões robustos entre parênteses, com correção de Abadie e Imbens (2016). O p valor se refere ao teste sob a hipótese nula de superestimação do efeito do tratamento.

\subsection{Função Dose-Resposta}

Após confirmar as hipóteses iniciais apresentadas neste trabalho, procuramos entender como os efeitos do PBF sobre os fluxos migratórios variam de acordo com os valores recebidos pelo programa. Os incentivos indiretos gerados pela política pública podem ser diferentes para cada indivíduo, uma vez que o volume de recursos recebido pelos indivíduos oriundos do programa não é o mesmo para todos. Logo, os impactos sobre a migração interna podem ser sensíveis aos valores transferidos pelo PBF aos seus participantes.

Para averiguar melhor esse aspecto, estimamos a Função Dose-Resposta (FDR) de Cerulli e Poti (2014), método pelo qual não se leva em consideração apenas o status binário do tratamento, mas também o nível de exposição do beneficiário ao programa medido aqui pelas transferências monetárias recebidas. Na Figura 3, percebemos que o efeito estimado do Bolsa Família sobre os fluxos 
migratórios é positivamente correlacionado com o valor monetário das transferências oriundas do programa.

Entretanto, apesar da inclinação positiva da FDR no Exercício I, à medida que se analisam níveis mais elevados de transferências oriundas do PBF o intervalo de confiança (95\%) da estimativa torna-se muito esparso, o que não garante a robustez dos efeitos. O resultado é esperado, uma vez que os indivíduos não conseguem prever ex ante o valor exato a ser recebido pelo programa, após remigração ao estado natal.

No Exercício II, os impactos estão amplamente correlacionados com as transferências monetárias oriundas do PBF. Para as dosagens iniciais, o efeito não é significativo sugerindo que a retenção de indivíduos no estado não é afetada no caso daqueles que recebam baixas transferências do PBF. Porém, quando o grau de exposição ao programa aumenta, o efeito torna-se cada vez maior e estatisticamente significante de acordo com o intervalo de confiança. Sendo assim, quanto maior é a renda não trabalho do indivíduo (aqui, medida pelas transferências do $\mathrm{PBF}$ ) maior é a chance dele ter permanecido no seu estado de residência nos últimos seis anos, o que pode ir ao encontro da hipótese de maximização de renda esperada apontada pelos modelos econômicos mainstream de migração se o impacto encontrado sobre estes fluxos for realmente oriundo de um efeito renda. ${ }^{19}$

Mesmo tendo utilizado um amplo conjunto de características individuais e domiciliares que se relacionam com o recebimento do PBF (renda per capita oriunda de trabalho, número de crianças, entre outros) nas estimações, pode-se questionar a dose utilizada (valor absoluto do programa) por carregar algum tipo de efeito seletivo a priori devido a outras características que envolvem o arranjo domiciliar dos beneficiários. Sendo assim, apresenta-se na figura 4 do Apêndice a FDR utilizando como dose o valor do benefício como proporção do orçamento domiciliar total. Os resultados são, de maneira geral, semelhantes aos anteriores. Variações positivas na dose não impactam os fluxos de remigração (intervalo de confiança sempre inclui o zero) e são positivamente correlacionados com o efeito retenção. Novamente, para as dosagens iniciais, este último efeito é próximo de zero, sugerindo que a fixação de indivíduos no estado não é afetada no caso daqueles cuja renda oriunda do programa representa pouco dentro do orçamento domiciliar. Mas, à medida que a importância do valor recebido do PBF cresce como razão da renda total, maior é o efeito de retenção por conta do programa.

19 Não objetivamos aqui aceitar (ou não) a hipótese de maximização de renda esperada, apenas sugerir uma possível correlação entre os resultados empíricos encontrados neste trabalho com a teoria econômica mainstream sobre migração. Tal aceitação requereria colocações teóricas que levassem em conta outros fatores que não apenas a renda, como características e comportamentos específicos aos grupos de interesse (população pobre e extremamente pobre). 
Figura 3 - Função dose-resposta (FDR/ATE) com intervalo de confiança
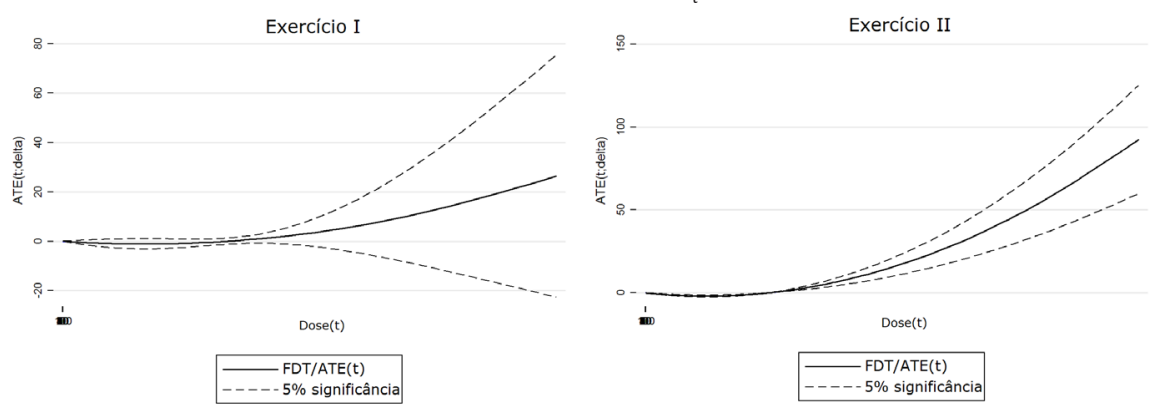

Fonte: Elaboração própria.

\section{Considerações Finais}

Este trabalho procurou evidências do efeito de programas de transferências de renda sobre a migração interestadual interna. Apesar de ambos estarem ligados ao desenvolvimento econômico de regiões, há poucas evidências sobre essa temática. Analisamos então a relação entre o Programa Bolsa Família e os fluxos migratórios internos no Brasil. Destacamos previamente dois efeitos possíveis: estímulo à remigração ao estado de origem, e efeito retenção de indivíduos em seus estados de moradia. As estimações foram feitas a partir dos dados do Censo Demográfico de 2010 por meio do Propensity Score Matching (PSM) e da Função Dose-Resposta (FDR).

Os resultados estimados parecem apontar para um efeito empírico de que programas de transferência de renda podem incentivar a volta de migrantes ao seu estado de origem. Dentre os indivíduos que migraram desde a criação do PBF, a probabilidade de os beneficiários do programa terem remigrado ao estado natal é 3 p.p superior à probabilidade dos não beneficiários do programa, semelhantes em diversas características observáveis.

Posteriormente, as outras estimações auferidas neste trabalho apontaram que os participantes do PBF, que já migraram no passado (antes da criação do programa) têm, em média, uma probabilidade de estarem fixos no estado em que residiam atualmente (pelo menos, desde a criação do PBF) 2,8 p.p. superior quando comparados aos não participantes do programa, pareados por meio do PSM. Este efeito retenção já havia sido achado por Silveira Neto (2008), em magnitude semelhante $(2,1 \%)$, só que ao comparar migrantes com não migrantes. Sendo assim, estendemos esse efeito para indivíduos também morando fora de seu estado de origem.

Em relação às estimações regionais, os maiores efeitos sobre remigração e retenção foram encontrados para região Nordeste, concentradora de beneficiários 
do PBF e de migrantes retornados. Impactos sobre a remigração também foram encontrados para as regiões Norte e Sudeste, e sobre a retenção para as regiões Norte, Centro-Oeste e Sul. Os resultados mais robustos foram aqueles estimados para o Norte e Nordeste, regiões mais carentes em termos socioeconômicos e que, sendo assim, dependem mais de programas sociais. Neste sentido, a renda oriunda do programa para indivíduos destas regiões pode ter maior relevância a ponto de impactar em maior magnitude as decisões migratórias.

Ainda, procuramos entender como os efeitos do PBF sobre os fluxos migratórios variam de acordo com os valores recebidos pelo programa. Através de estimações auferidas a partir da Função Dose-Resposta (FDR) mostramos que os efeitos do programa sobre a migração são positivamente correlacionados com o valor do beneficio oriundo do PBF. Entretanto, para migração de retorno a variação positiva da FDR de acordo com estes valores não se mostra significativa a 5\%. Já o efeito de retenção é amplamente correlacionado com as quantias monetárias pagas pelo programa e, sendo assim, quanto maior é a renda do indivíduo oriunda do PBF, maior é a chance dele estar fixo em um estado específico. Os modelos econômicos mainstream de migração apontam que esta decisão é oriunda de um comportamento de maximização de renda esperada por parte dos indivíduos. Nesse sentido, o fato de os efeitos estimados neste trabalho serem acentuados para indivíduos com maiores valores monetários recebidos pelo PBF pode estar correlacionado com a teoria econômica.

Como em qualquer estudo empírico a respeito de avaliação de políticas, as relações aqui encontradas carecem de mais estudo. Uma possível limitação é estarmos trabalhando com dados de cross-section, no qual sabemos apenas da situação de tratamento, em julho de 2010 , e a classificação do indivíduo quanto à migração. Entretanto esta última é baseada no que os indivíduos fizeram no passado e não sabemos, ao certo, a data em que estes passaram a ser beneficiários do PBF. Para que se possa aprimorar o estudo das relações entre programas de transferência de renda e migração interna, incentivamos então que os próximos trabalhos sejam realizados a partir de dados longitudinais que permitam acompanhar o individuo.

\section{Referências}

ABADIE, A.; IMBENS, G. W. Large sample properties of matching estimators for average treatment effects. Econometrica, n. 74, p. 235-267, 2006.

. Bias-corrected matching estimators for average treatment effects. Journal of Business and Economic Statistics, n.29, p. 1-11, 2011.

. Matching on the estimated propensity score. Econometrica, n. 84, p. 781-807, 2016. 
AKVIK, A. Bounding a Matching Estimator: The case of Norwegian Training Program. Oxford Bulletin of Economics and Statistics, v. 1, n.63, p. 115-143, 2001.

ANGELUCCI, M. Migration and credit constraints: Evidence from Mexico. Labour, v. 1, n. 26, p.1-54, 2011.

ARAUJO, G. S.; RIBEIRO, R.; NEDER, H. D. Impactos do Programa Bolsa Família sobre o trabalho de crianças e adolescentes residentes na área urbana em 2006. Revista EconomiA, v. 11, n. 4, p. 57-102, 2010.

BRASIL. Lei $n^{0}$ 10.836, de 9 de janeiro de 2004. Cria o Programa Bolsa Família e dá outras providências. 2004. Disponível em: < http://www.planalto.gov.br/ccivil_03/_Ato20042006/2004/Lei/L10.836.htm>. Acesso em: 20 ago. 2016.

. Ministério do Desenvolvimento Social e Combate à Fome. Secretaria Nacional de Renda de Cidadania. Instrução Operacional $n^{\circ} 12$ SENARC/MDS, de 3 de fevereiro de 2006. Divulga aos municípios orientações sobre a repercussão automática de alterações cadastrais do Cadastro Único de Programas Sociais do Governo Federal no Sistema de Gestão de Benefícios do Programa Bolsa Família. Disponível em: <http:/www.mds.gov. br/webarquivos/legislacao/bolsa_familia/instrucoes_operacionais/2006/Instrucao\%20 Operacional\%2012\%20senarc.pdf> $>$. Acesso em: 20 ago. 2016.

BORJAS, G. J. Self-selection and the earnings of immigrants. American Economic Review, v. 77, n. 4, p. 531-553, 1987.

BORJAS, G. J; BRATSBERG, B. Who leaves? The outmigration of the Foreign-Born. The Review of Economics and Statistics, v. 87, n. 1, p. 165-176, 1996.

BRAW, A. et al. The impact of Bolsa Família on Schooling. World Development, v. 70, p. 303-326, 2015.

BRITO, F. R. A.; CARVALHO, J. A. M. As migrações internas no Brasil: as novidades sugeridas pelos censos demográficos de 1991 e 2000 e pelas PNADs recentes. Parcerias Estratégicas, n. 22, p. 441-455, 2006.

CAVALCANTI, D. M. et al. Impactos do Programa Bolsa Família na renda e na oferta de trabalho das famílias pobres: Uma abordagem usando o efeito quantílico de tratamento. Economia Aplicada, v. 20, n. 2, p. 173-201, 2016.

CECHIN, L. A. W. et al. O impacto das regras do Programa Bolsa Família sobre a fecundidade das beneficiárias. Revista Brasileira de Economia, Rio de Janeiro, v. 69, n. 3, p. 303-329, 2015.

CERULLI, G. Command for fitting dose-response models under exogenous and endogenous treatment. The Stata Journal, v. 15, n. 4, p. 1019-1045, $2015 \mathrm{~b}$.

. Econometric evaluation of socio-economic programs. Springer, Advanced Studies in Theoretical and Applied Econometrics, v. 49, $2015 \mathrm{a}$.

CERULLI, G.; POTI, B. Public support intensity and company RED performance: Evidence from a dose-response model. In: CONGRESS OF EUROPEAN REGIONAL SCIENCE ASSOCIATION, 54, 2014, São Petesburgo/Russia. Anais. São Petesburgo: ERSA, 2014. 
CHITOLINA, L.; FOGUEL, M. N.; MENEZES-FILHO, N. A. The Impact of the expansion of the Bolsa Familia Program on the time allocation of youths and their parents. Revista Brasileira de Economia, v. 70, n. 2, p. 183-202, 2016.

CUNHA, A. S. Migração de retorno num contexto de crises, mudanças e novos desafios. In: ENCONTRO NACIONAL DE ESTUDOS POPULACIONAIS DA ABEP, 12., 2000, Caxambu, MG. Anais... Caxambu: ABEP, 2000. v. 1.

DUSTMANN, C. Return migration, wage differentials, and the optimal migration duration. European Economic Review, v. 47, n. 2, p. 353-369, 2003.

DUSTMANN, C.; KIRCHKAMP, O. The optimal migration duration and activity choice after re-migration. Journal of Development Economics, v. 2, n. 67, p. 351-372, 2002.

DUSTMANN, C.; MESTRES, J. Remittances and temporary migration. Journal of Development Economics, v. 92, n. 1, p. 62-70, 2010.

FAZITO, D. A configuração estrutural dos arranjos familiares nos processos migratórios: A força dos laços fortes para a intermediação. REBEP, v. 25, n. 2, 2008.

. Análise de redes sociais e migração: Dois aspectos fundamentais do "retorno." $\overline{R e v i s t a ~ B r a s i l e i r a ~ d e ~ C i e ̂ n c i a s ~ S o c i a i s . ~ v . ~ 25, ~ n . ~ 72, ~ p . ~ 89-100, ~} 2010$.

HARRIS, J. R.; TODARO, M. P. Migration, unemployment and development: a two-sector analysis. American Economic Review, v. 60, n. 1, p. 126-142, 1970.

HECKMAN, J. et al. Characterizing selection bias using experimental data. Econometrica, v. 66, n. 5, p. 1017-1098, 1998.

IBGE. Censo Demográfico 2010. Rio de Janeiro: IBGE, 2010. Disponível em: < http:// censo2010.ibge.gov.br>. Acesso em: 20 ago. 2016.

IMBENS, G. W.; WOOLDRIDGE, J. M. Recent developments in the econometrics of program evaluation. Journal of Economic Literature, v. 47, n. 1, p. 5-86, 2009.

MIRANDA-RIBEIRO, A.; GARCIA, R. A.; LOBO, C. Efeitos diretos e indiretos da migração de retorno no Brasil nos anos 2000. Caderno de Geografia, v. 26, n. 47, p. 672-683 2016.

NASCIMENTO, A. R.; KASSOUF, A. L. O impacto do Programa Bolsa Família sobre a decisão de trabalho das crianças: uma análise utilizando os microdados da PNAD. Análise Economia, Porto Alegre, n. 66, p. 225-254, 2016.

OLIVEIRA, K.; JANUZZI, P. M. Motivos para migração no Brasil e retorno ao Nordeste: Padrões etários, por sexo e origem/destino. São Paulo em Perspectiva, São Paulo, v. 9, n. 4, p. 134-143, 2005.

QUEIROZ, S. N.; BAENINGER, R. Migração de retorno: o caso recente das migrações cearenses. Revista Econômica do Nordeste, v. 44, n. 4, p. 833-850, 2013.

RAMALHO, H. M. B.; QUEIROZ, V. S. Migração interestadual de retorno e autosseleção: Evidências para o Brasil. Pesquisa e planejamento econômico, Rio de Janeiro, v. 41, n. 3, p. 369-396, 2011. 
ROSENBAUM, P. R. Observational Studies. 2. ed. Nova York: Springer, 2002.

ROSENBAUM, P. R.; RUBIN, D. B. The central role of the propensity score in observational studies for causal effects. Biometrika, v. 70, n. 1, p. 41-55, 1983.

SACHSIDA, A.; CAETANO, M. A.; ALBUQUERQUE, P. Distribuição de renda, transferências federais e imigração: Um estudo de dados em painel para as unidades de federação do Brasil. Brasília: Ipea, 2010. (Texto para discussão, 1471).

SANTOS JÚNIOR, E. R.; MENEZES-FILHO, N.; FERREIRA, P. C. Migração, seleção e diferenças regionais de renda no Brasil. Pesquisa e Planejamento Econômico, v. 35, n. 3, p. 229-331, 2005.

SILVEIRA NETO, R. Do public income transfer to the poorest affect internal inter-regional migration? Evidence for the case of Brazilian Bolsa Familia Program. In: ENCONTRO NACIONAL DE ECONOMIA, 36., 2008, Salvador. Anais... Salvador: Anpec, 2008.

SOARES, S.; SÁTYRO, N. O Programa Bolsa Família: desenho institucional e as possibilidades futuras. In: CASTRO, J. A.; MODESTO, L. (Org.). Programa Bolsa Família 2003-2010: Avanços e Desafios. Brasília, DF: Ipea, 2010.

SOARES, W. Análise de redes sociais e os fundamentos teóricos da migração internacional. REBEP, Campinas, v. 21, n. 1, p. 101-116, 2004.

STECKLOV, G. et al. Do conditional cash transfers influence migration? A study using experimental data from the Mexican PROGRESA Program. Demography, v. 42, n. 4, p. 769$90,2005$.

TAVARES; P.A. Efeito do Programa Bolsa Família sobre a oferta de trabalho das mães. Economia e Sociedade, Campinas, v. 19, n. 30, p. 613-625, 2010.

VASCONCELOS, A. M. et al. Programa Bolsa Família e geração "nem-nem": evidências para o Brasil. Revista Brasileira de Economia, Rio de Janeiro, v. 71, n. 2, p. 233-257, 2017.

VREYER, P.; GUBERT, F.; ROBILLIARD, A-S. Are there returns to migration experience? An empirical analysis using data on return migrants and non-migrants in West Africa. Annals of Economics and Statistics, Migration and Development, n. 97/98, p. 307-328, 2010.

WOOLDRIDGE, J. M. Econometric analysis of cross section and panel data. 2. ed. Cambridge, MA: MIT Press, 2010. 


\section{Apêndice A}

Tabela 9- Modelo logit - probabilidade de participação no PBF

\begin{tabular}{|c|c|c|c|}
\hline Variável & Coeficiente & Variável & Coeficiente \\
\hline \multirow[t]{2}{*}{ Idade } & $0.235 * *$ & Economicamente Inativo & $-0.124 * *$ \\
\hline & $(0.0045)$ & & $(0.042)$ \\
\hline \multirow[t]{2}{*}{ Idade $^{2}$} & $-0.00356 * *$ & Desempregado & (omitida) \\
\hline & $(0.000)$ & Pessoas domicílio $<=15$ anos & $0.525 * *$ \\
\hline \multirow[t]{2}{*}{ Casado } & 0.012 & & $(0.0049)$ \\
\hline & $(0.0054)$ & Pessoas domicílio $>15$ anos & 0.0067 \\
\hline \multirow[t]{2}{*}{ Negro/Pardo } & $0.2576 * *$ & & $(0.0043)$ \\
\hline & $(0.0075)$ & Índice de posse & $-0.4055 * *$ \\
\hline \multirow[t]{2}{*}{ Indígena } & 0.0354 & & $(0.0059)$ \\
\hline & $(0.0352)$ & Renda domiciliar per capita & $-0.00185 * *$ \\
\hline Branco & (omitida) & & $(0.0002)$ \\
\hline \multirow[t]{2}{*}{ Chefe de domicílio } & $0.2104 * *$ & Densidade do domicilio & $0.095 * *$ \\
\hline & $(0.0048)$ & & $(0.0052)$ \\
\hline \multirow[t]{2}{*}{ Cônjuge } & $-0.654 * *$ & Domicilio próprio & $0.1568^{*}$ \\
\hline & $(0.0154)$ & & $(0.0756)$ \\
\hline \multirow[t]{2}{*}{ Homem } & $3.120 * *$ & Domicilio próprio não pago & -0.047 \\
\hline & $(0.024)$ & & $(0.0512)$ \\
\hline \multirow[t]{2}{*}{ Fundamental incompleto } & $1.802 * *$ & Domicilio alugado & -0.015 \\
\hline & $(0.0576)$ & & $(0.1054)$ \\
\hline \multirow[t]{2}{*}{ Fundamental completo } & $1.452 * *$ & $\begin{array}{l}\text { Domicilio cedido por } \\
\text { empregador }\end{array}$ & 0.0248 \\
\hline & $(0.052)$ & & $(0.0612)$ \\
\hline \multirow[t]{2}{*}{ Médio completo } & $1.001 * *$ & $\begin{array}{l}\text { Domicilio cedido de outra } \\
\text { forma }\end{array}$ & $0.089 * *$ \\
\hline & $(0.0521)$ & & $(0.0354)$ \\
\hline Superior completo & (omitida) & Outra condição domiciliar & (omitida) \\
\hline \multirow[t]{2}{*}{$\begin{array}{l}\text { Trabalhador carteira } \\
\text { assinada }\end{array}$} & $-0.691 * *$ & Metrópole & $-0.420 * *$ \\
\hline & $(0.0428)$ & & $(0.0201)$ \\
\hline
\end{tabular}




\begin{tabular}{lclc}
\hline Vonclusão & Coeficiente & Variável & Coeficiente \\
\hline Funcionário público & $-0.398^{* *}$ & Urbana & $-0.142^{* *}$ \\
& $(0.0594)$ & & $(0.0024)$ \\
Trabalhador informal & $0.092^{* *}$ & Tempo de moradia na UF & $0.0498^{* *}$ \\
& $(0.0357)$ & & $(0.0055)$ \\
Trabalhador Autônomo & 0.0478 & Constante & $-7.887^{* *}$ \\
& $(0.086)$ & & $(0.115)$ \\
Empregador & $-0.914^{* *}$ & & \\
& $(0.196)$ & & \\
\hline Pseudo R2 & 0.31 & & \\
Observações & 349,754 & & \\
\hline
\end{tabular}

Fonte: Elaboração própria.

Nota: ** $\mathrm{p}<0.01,{ }^{*} \mathrm{p}<0.05$. Em parênteses, erros padrões. O modelo inclui ainda dummies de UF.

Tabela 10 - Médias e diferenças das médias normalizadas das variáveis para tratados e controles, após o pareamento (amostra migração de última etapa)

\begin{tabular}{lccc}
\hline \multicolumn{1}{c}{ Variável } & Controles & Tratados & Diferença Normalizada \\
\hline Idade & 33.64686 & 33.52564 & -0.00933 \\
Idade $^{2}$ & 1222.774 & 1201.990 & -0.02147 \\
Casado & 0.37541 & 0.37800 & 0.00378 \\
Branco & 0.29555 & 0.31606 & -0.02051 \\
Negro/Padro & 0.70065 & 0.68745 & 0.01320 \\
Indígena & 0.00380 & 0.00120 & 0.00260 \\
Chefe de domicílio & 0.56486 & 0.54860 & 0.01626 \\
Cônjuge & 0.36743 & 0.34252 & 0.02491 \\
Filho & 0.06771 & 0.05760 & 0.01011 \\
Homem & 0.09010 & 0.05410 & -0.09819 \\
Fundamental incompleto & 0.63091 & 0.65578 & 0.03671 \\
Fundamental completo & 0.21327 & 0.20011 & -0.02297 \\
Médio completo & 0.14788 & 0.13667 & -0.02269 \\
Superior completo & 0.00794 & 0.00744 & -0.00411 \\
Sem emprego & 0.34790 & 0.63892 & 0.02010 \\
Trabalhador carteira assinada & 0.06750 & 0.06004 & -0.04922 \\
\hline
\end{tabular}

continua... 


\begin{tabular}{lccc}
\hline \multicolumn{1}{c}{ Variável } & Controles & Tratados & Diferença Normalizada \\
\hline Funcionário público & 0.01080 & 0.00925 & -0.01097 \\
Trabalhador informal & 0.18760 & 0.20396 & 0.01211 \\
Trabalhador autônomo & 0.08886 & 0.08724 & -0.00408 \\
Empregador & 0.00030 & 0.00059 & 0.00820 \\
Economicamente Inativo & 0.29704 & 0.25776 & 0.03928 \\
Pessoas domicílio <=15 anos & 1.77899 & 1.94209 & 0.08387 \\
Pessoas domicílio >15 anos & 2.61536 & 2.55707 & -0.03422 \\
Índice de posse & 0.33624 & 0.40406 & -0.05333 \\
Renda domiciliar per capita & 74.62838 & 68.10347 & -0.05404 \\
Densidade do domicilio & 0.97543 & 1.00768 & 0.03379 \\
Domicilio próprio & 0.57245 & 0.58672 & 0.02045 \\
Domicilio próprio não pago & 0.02465 & 0.02317 & -0.00683 \\
Domicilio alugado & 0.24246 & 0.22346 & -0.03178 \\
Domicilio cedido por empre- & 0.04902 & 0.04557 & -0.01149 \\
gador & & & 0.02457 \\
Domicilio cedido de outra & 0.10015 & 0.11082 & -0.00701 \\
forma & & 0.01025 & -0.03480 \\
Outra condição domiciliar & 0.01127 & 0.17685 & -0.04134 \\
Metrópole & 0.19602 & 0.69845 & 0.00833 \\
Urbana & 0.72495 & 4.53353 & \\
Tempo de moradia na UF & 4.49830 & & \\
\hline Fone: Elaboraça prop & & & \\
\hline
\end{tabular}

Fonte: Elaboração própria.

Nota: As 27 dummies referentes às unidades da federação foram omitidas por motivos de concisão, mas, assim como as demais variáveis, satisfizeram o critério de balanceamento.

Tabela 11 - Modelo logit - probabilidade de participação no PBF

\begin{tabular}{lclc}
\hline Variável & Coeficiente & Variável & Coeficiente \\
\hline Idade & $0.245^{* *}$ & Economicamente Inativo & $-0.128^{* *}$ \\
& $(0.0024)$ & & $(0.030)$ \\
Idade $^{2}$ & $-0.00367^{* *}$ & Desempregado & $($ omitida $)$ \\
& $(0.000)$ & Pessoas domicílio $<=15$ anos & $0.357^{* *}$ \\
Casado & 0.008 & & $(0.0013)$ \\
& $(0.0082)$ & Pessoas domicílio $>15$ anos & -0.0007 \\
Negro/Pardo & $0.2457^{* *}$ & & $(0.0033)$ \\
& $(0.0045)$ & Índice de posse & $-0.4005^{* *}$ \\
\hline
\end{tabular}


conclusão.

\begin{tabular}{|c|c|c|c|}
\hline Variável & Coeficiente & Variável & Coeficiente \\
\hline \multirow[t]{2}{*}{ Indígena } & 0.0375 & & $(0.005)$ \\
\hline & $(0.0352)$ & Renda domiciliar per capita & $-0.00098 * *$ \\
\hline Branco & (omitida) & & $(0.0001)$ \\
\hline \multirow[t]{2}{*}{ Chefe de domicílio } & $0.1204^{* *}$ & Densidade do domicilio & $0.095 * *$ \\
\hline & $(0.0048)$ & & $(0.0042)$ \\
\hline \multirow[t]{2}{*}{ Cônjuge } & $-0.565 * *$ & Domicilio próprio & $0.0568 * *$ \\
\hline & $(0.0154)$ & & $(0.0375)$ \\
\hline \multirow[t]{2}{*}{ Homem } & $3.127^{* *}$ & Domicilio próprio não pago & $-0.147^{* *}$ \\
\hline & $(0.015)$ & & $(0.0423)$ \\
\hline \multirow[t]{2}{*}{$\begin{array}{l}\text { Fundamental incom- } \\
\text { pleto }\end{array}$} & $1.837^{* *}$ & Domicilio alugado & $-0.435 * *$ \\
\hline & $(0.0452)$ & & $(0.0487)$ \\
\hline \multirow[t]{2}{*}{ Fundamental completo } & $1.586 * *$ & Domicilio cedido por empregador & $0.248 * *$ \\
\hline & $(0.0436)$ & & $(0.0414)$ \\
\hline \multirow[t]{2}{*}{ Médio completo } & $1.029 * *$ & Domicilio cedido de outra forma & $0.089 * *$ \\
\hline & $(0.0428)$ & & $(0.0245)$ \\
\hline Superior completo & (omitida) & Outra condição domiciliar & (omitida) \\
\hline \multirow[t]{2}{*}{$\begin{array}{l}\text { Trabalhador carteira } \\
\text { assinada }\end{array}$} & $-0.691 * *$ & Metrópole & $-0.417^{* *}$ \\
\hline & $(0.0305)$ & & $(0.0102)$ \\
\hline \multirow[t]{2}{*}{ Funcionário público } & $-0.437 *$ & Urbana & $-0.134 * *$ \\
\hline & $(0.0531)$ & & $(0.0012)$ \\
\hline \multirow[t]{2}{*}{ Trabalhador informal } & $0.102 * *$ & Tempo de moradia na UF & $0.00367 * *$ \\
\hline & $(0.029)$ & & $(0.0004)$ \\
\hline \multirow[t]{2}{*}{ Trabalhador Autônomo } & 0.0478 & Constante & $-7.387 * *$ \\
\hline & $(0.077)$ & & $(0.075)$ \\
\hline \multirow[t]{2}{*}{ Empregador } & $-1.014^{* *}$ & & \\
\hline & $(0.123)$ & & \\
\hline Pseudo $\mathrm{R}^{2}$ & 0.33 & & \\
\hline Observações & $1,629,923$ & & \\
\hline
\end{tabular}

Fonte: Elaboração própria.

Nota: ** $\mathrm{p}<0.01,{ }^{*} \mathrm{p}<0.05$. Em parênteses, erros padrões. O modelo inclui ainda dummies de UF. 
Tabela 12 - Médias e diferenças das médias normalizadas das variáveis para tratados e controles, após o pareamento

\begin{tabular}{|c|c|c|c|}
\hline Variável & Controles & Tratados & $\begin{array}{c}\text { Diferença } \\
\text { Normalizada }\end{array}$ \\
\hline Idade & 33.01109 & 32.90565 & -0.00806 \\
\hline Idade $^{2}$ & 1180.914 & 1162.850 & -0.01870 \\
\hline Casado & 0.37032 & 0.37566 & 0.00781 \\
\hline Branco & 0.23666 & 0.28978 & -0.05312 \\
\hline Negro/Padro & 0.75424 & 0.68745 & 0.06679 \\
\hline Indígena & 0.00910 & 0.00120 & 0.00790 \\
\hline Chefe de domicílio & 0.57578 & 0.54860 & 0.02718 \\
\hline Cônjuge & 0.36670 & 0.32706 & 0.03964 \\
\hline Filho & 0.05752 & 0.08572 & -0.02820 \\
\hline Homem & 0.09024 & 0.05527 & -0.09498 \\
\hline Fundamental incompleto & 0.64158 & 0.65947 & 0.02652 \\
\hline Fundamental completo & 0.20917 & 0.19965 & -0.01671 \\
\hline Médio completo & 0.14197 & 0.13470 & -0.01488 \\
\hline Superior completo & 0.00727 & 0.00618 & -0.00942 \\
\hline Desempregado & 0.34284 & 0.35833 & 0.02297 \\
\hline Trabalhador carteira assinada & 0.08703 & 0.07507 & -0.03098 \\
\hline Funcionário público & 0.00699 & 0.00674 & -0.00217 \\
\hline Trabalhador informal & 0.18337 & 0.18464 & 0.00231 \\
\hline Trabalhador autônomo & 0.07858 & 0.07449 & -0.01088 \\
\hline Empregador & 0.00118 & 0.00073 & -0.01038 \\
\hline Economicamente Inativo & 0.30001 & 0.24864 & 0.05137 \\
\hline Pessoas domicílio $<=15$ anos & 1.82707 & 1.96563 & 0.06706 \\
\hline Pessoas domicílio > 15 anos & 2.66361 & 2.60971 & -0.02811 \\
\hline Índice de posse & 0.35660 & 0.40748 & -0.03911 \\
\hline Renda domiciliar per capita & 78.58107 & 73.16663 & -0.04311 \\
\hline Densidade do domicilio & 1.03034 & 1.05634 & 0.02541 \\
\hline Domicilio próprio & 0.45325 & 0.47329 & 0.02841 \\
\hline Domicilio próprio não pago & 0.02621 & 0.02421 & -0.00900 \\
\hline Domicilio alugado & 0.34753 & 0.32515 & -0.03349 \\
\hline Domicilio cedido por empregador & 0.06652 & 0.06137 & -0.01487 \\
\hline Domicilio cedido de outra forma & 0.09723 & 0.10689 & 0.02256 \\
\hline Outra condição domiciliar & 0.00926 & 0.00909 & -0.00132 \\
\hline
\end{tabular}


conclusão.

\begin{tabular}{lccc}
\hline \multicolumn{1}{c}{ Variável } & Controles & Tratados & $\begin{array}{c}\text { Diferença } \\
\text { Normalizada }\end{array}$ \\
\hline Metrópole & 0.22409 & 0.20865 & -0.02651 \\
Urbana & 0.73528 & 0.72061 & -0.02331 \\
Tempo de moradia na UF & 2.72756 & 2.80448 & 0.02706 \\
\hline
\end{tabular}

Fonte: Elaboração própria.

Nota: As 27 dummies referentes às unidades da federação foram omitidas por motivos de concisão, mas, assim como as demais variáveis, satisfizeram o critério de balanceamento.

Tabela 13 - Proporção de beneficiários do PBF, migrantes de longo prazo, migrantes de retorno e demais migrantes por região

\begin{tabular}{lccccc}
\hline \multicolumn{1}{c}{ Grupos de Análise } & Norte & Nordeste & Centro-Oeste & Sudeste & Sul \\
\hline PBF & $24.80 \%$ & $32.00 \%$ & $14.22 \%$ & $23.18 \%$ & $5.80 \%$ \\
Migrante de longo prazo & $15.87 \%$ & $16.10 \%$ & $16.12 \%$ & $39.21 \%$ & $12.70 \%$ \\
Migrante de retorno & $12.78 \%$ & $40.72 \%$ & $11.82 \%$ & $25.96 \%$ & $8.71 \%$ \\
Demais migrantes & $17.40 \%$ & $28.99 \%$ & $16.11 \%$ & $30.29 \%$ & $7.21 \%$ \\
\hline
\end{tabular}

Fonte: Elaboração própria com base nos microdados do Censo 2010.

Tabela 14 - Impacto do PBF (ATT) sobre a migração de retorno (Exercício I) e retenção (Exercício II) pelo estimador IPW

\begin{tabular}{lcc}
\hline \multicolumn{1}{c}{ Região } & Exercício I & Exercício II \\
\hline \multirow{2}{*}{ Brasil } & $0.038 * * *$ & $0.045^{* * *}$ \\
& $(0.005)$ & $(0.018)$ \\
\hline Observações & 348,109 & $1,629,923$ \\
\hline \multirow{2}{*}{ Norte } & $0.020 * *$ & $0.031 * *$ \\
& $(0.008)$ & $(0.008)$ \\
\hline Observações & 40,870 & 267,941 \\
\hline \multirow{2}{*}{ Nordeste } & $0.048 * * *$ & $0.045 * *$ \\
\hline Observações & $(0.006)$ & $(0.004)$ \\
\hline \multirow{2}{*}{ Centro-Oeste } & 95,072 & 324,887 \\
\hline Observações & 0.006 & $0.027 * *$ \\
\hline & $(0.007)$ & $(0.005)$ \\
\hline
\end{tabular}


conclusão.

\begin{tabular}{lcc}
\hline \multicolumn{1}{c}{ Região } & Exercício I & Exercício II \\
\hline \multirow{2}{*}{ Sudeste } & 0.006 & 0.010 \\
& $(0.006)$ & $(0.023)$ \\
\hline Observações & 108,570 & 593,243 \\
\hline \multirow{2}{*}{ Sul } & 0.121 & $0.013 * * *$ \\
& $(0.130)$ & $(0.004)$ \\
\hline Observações & 51,030 & 201,280 \\
\hline
\end{tabular}

Fonte: Elaboração própria.

Nota: ${ }^{* * *} \mathrm{p}<0.01,{ }^{* *} \mathrm{p}<0.05,{ }^{*} \mathrm{p}<0.1$. Erros padrões robustos entre parênteses.

Figura 4 - Função dose-resposta (FDR/ATE $)$ com intervalo de confiança
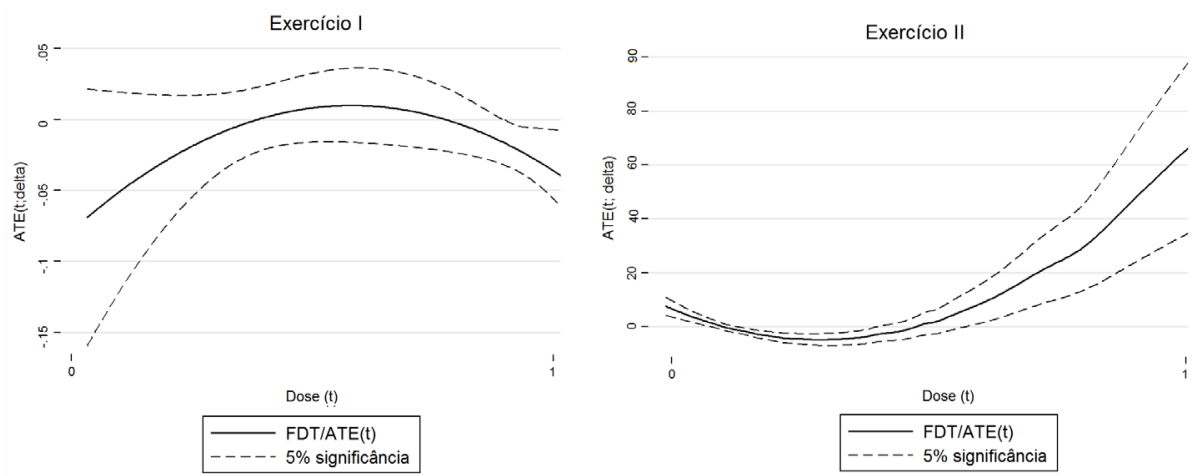

Fonte: Elaboração própria.

Nota: A dose aqui utilizada é a razão entre o valor recebido pelo PBF e o orçamento domiciliar total.

Recebido em: 23/01/2017. Aceito em: 14/08/2017. 